\title{
New studies and a short review of heavy neutron-rich transfer products
}

\author{
H. M. Devaraja ${ }^{1,2, a}$, S. Heinz ${ }^{1,2}$, D. Ackermann ${ }^{3}$, T. Göbel ${ }^{1}$, F. P. Heßberger ${ }^{2,4}$, S. Hofmann ${ }^{2}$, J. Maurer ${ }^{2}$, \\ G. Münzenberg ${ }^{2}$, A. G. Popeko ${ }^{5}$, A. V. Yeremin ${ }^{5}$ \\ ${ }^{1}$ Justus-Liebig-Universität Giessen, II. Physikalisches Institut, 35392 Gießen, Germany \\ ${ }^{2}$ GSI Helmholtzzentrum für Schwerionenforschung GmbH, 64291 Darmstadt, Germany \\ ${ }^{3}$ GANIL, CEA/DRF-CNRS/IN2P3, BP 55027, 14076 Caen Cedex 5, France \\ ${ }^{4}$ Helmholtz-Institut Mainz, 55099 Mainz, Germany \\ ${ }^{5}$ Joint Institute for Nuclear Research, 141980 Dubna, Russia
}

Received: 26 May 2020 / Accepted: 17 August 2020 / Published online: 5 September 2020

(C) The Author(s) 2020

Communicated by Nicolas Alamanos

\begin{abstract}
We present new results on multi-nucleon transfer reactions in low-energy collisions of ${ }^{48} \mathrm{Ca}+{ }^{238} \mathrm{U}$ measured at the velocity filter SHIP of GSI Helmholtz Centre, where we observed around 90 different nuclides from $\mathrm{Tl}$ to $\operatorname{Am}(Z=$ 81-95). We followed the idea to use uranium targets for the synthesis of neutron-rich MNT products, particularly in the region below lead, which was triggered by model calculations. The $\gamma, \alpha$ and spontaneous fission activities of the populated nuclides have been analyzed for their identification. The cross-sections of the observed isotopes for elements $Z=81-$ 93 as a function of their mass number have been investigated. Excitation energy, total kinetic energy and the influence of nuclear shell effects on the production cross-sections of the observed transfer products have been studied. Also we present a compact review and comparative analysis of various multi-nucleon transfer and fragmentation reactions which are aimed at the synthesis of neutron-rich nuclides along the $N=126$ shell closure in heavy nuclei.
\end{abstract}

\section{Introduction}

Exploring the heavy neutron-rich nuclei and their decay sequences to the valley of $\beta$ stability is supremely interesting for the understanding of the predicted $r$-process path. Indeed, the evolution of the nuclear shells far from the valley of stability and along the neutron shell $N=126$ is still an open question. The most neutron-rich nuclei in this area were so far produced by using ${ }^{208} \mathrm{~Pb}$ and ${ }^{238} \mathrm{U}$ fragmentation reactions. They reached the cross-section level down to picobarns $[1,2]$. In these experiments, cross-sections are decreasing very steeply after stripping of every proton along $N=126$. Presently, the nucleus ${ }_{76}^{202} \mathrm{Os}$ is the lightest $N=126$ isotone with a production cross-section of $4.4 \pm 2.0 \mathrm{pb}$ [2].

Multi-nucleon transfer (MNT) reactions, which are under discussions for the past few decades, established new expectations to reach the still unknown region of neutron-rich $N=$ 126 nuclei. This is based on the results of so far performed experiments [3-24] as well as on predictions based on various theoretical models, such as the di-nuclear system (DNS) model [25-33], model based on Langevin-type dynamical equations [34-39], GRAZING model [40,41], complex Wentzel-Kramers-Brillouin (CWKB) model [42], improved quantum molecular dynamics model (ImQMD) [43-47], time-dependent Hartree-Fock (TDHF) theory $[48,49]$, and others (see, e.g., reviews [50-53] and references therein).

Model calculations based on the Langevin-type dynamical equations of motion given in [37] recommend to use deep inelastic MNT reactions in ${ }^{136} \mathrm{Xe}+{ }^{208} \mathrm{~Pb}$ and estimated larger cross-sections than that of fragmentation reactions. Other theoretical results from the DNS model [29] proposed to apply MNT reactions with neutron-rich lighter beams like ${ }^{48} \mathrm{Ca}$ or ${ }^{64} \mathrm{Ni}$. Experimental results exist already for both variants. An interesting alternative approach of the DNS model is the suggestion to use uranium targets instead of $\mathrm{Pb}$ or $\mathrm{Pt}$ to populate nuclei along $N=126$. With $\mathrm{Pb}$ or Pt targets the nucleon flow must proceed in south-east direction of the nuclide chart to populate neutron-rich nuclei along $N=126$. But with uranium or other actinide targets, the same nuclides can be reached with the much more preferred south-west flow of nucleons, along the stability line. This should shift the isotopic distributions toward the neutron-rich side. These

a e-mail: d.haleshappamalligenahalli@gsi.de (corresponding author) 
DNS model results motivated our experimental investigation of the $\mathrm{Ca}+\mathrm{U}$ system.

Already in the 1980 s, MNT reactions were applied successfully at the GSI on-line mass separator to synthesize heavy nuclei. Various reactions with heavy beams like ${ }^{76} \mathrm{Ge}$ $[54,55],{ }^{136} \mathrm{Xe}[56-58],{ }^{186} \mathrm{~W}[59,60],{ }^{208} \mathrm{~Pb}[61]$ and ${ }^{238} \mathrm{U}$ [62] on tantalum and tungsten targets were applied. They lead to the discovery of 18 isotopes with $Z=25-89$ on the neutron-rich side of the nuclide chart. The nuclides were identified and investigated by coincident detection of their $\gamma$ and X-ray decay activities.

At the velocity filter SHIP of GSI we performed extensive studies of MNT reactions over the past years [12-23] aiming at different areas of heavy and superheavy nuclei on the nuclide chart. In one of our more recent works, MNT reactions were successfully applied to synthesize new neutron-deficient uranium and trans-uranium isotopes, and to populate heavy neutron-rich nuclei up to nobelium in ${ }^{48} \mathrm{Ca}+{ }^{248} \mathrm{Cm}$ collisions. In other studies, we used ${ }^{58,64} \mathrm{Ni}$ beams with ${ }^{207} \mathrm{~Pb}$ targets, to investigate below-Pb MNT products [19] and observed several isotopes of elements down to $Z=76$. The results are very similar to the ones of other groups who investigated this region with $\mathrm{Pb}$ or $\mathrm{Pt}$ targets [63-65]. Significant attention is presently drawn to recent results presented in [66] who studied the MNT reactions in ${ }^{136} \mathrm{Xe}+{ }^{198} \mathrm{Pt}$ collisions. They detected the projectile-like fragments and deduced from them the isotopic distributions of the complementary target-like fragments. It was revealed that MNT cross-sections strongly increase with respect to fragmentation cross-sections toward smaller proton numbers. It is an interesting goal for future experiments to confirm these results by directly detecting the target-like MNT products.

In this article we present our experimental results from MNT reactions in ${ }^{48} \mathrm{Ca}+{ }^{238} \mathrm{U}$, suggested by DNS model calculations to synthesize neutron-rich nuclei below $\mathrm{Pb}$. The populated target-like nuclei have been identified using their $\alpha, \gamma$ and spontaneous fission (SF) activities. We investigated isotopic distributions, excitation energy, total kinetic energy and influence of nuclear shell effects on the production cross-sections of the observed transfer products. The results are compared with previously studied $\mathrm{MNT}$ reactions in the systems ${ }^{64} \mathrm{Ni}+{ }^{207,208} \mathrm{~Pb}[19,63],{ }^{136} \mathrm{Xe}+{ }^{208} \mathrm{~Pb}$ [64], ${ }^{136} \mathrm{Xe}+{ }^{198} \mathrm{Pt}[65,66]$ and with fragmentation reactions using ${ }^{208} \mathrm{~Pb}[1,67]$ and ${ }^{238} \mathrm{U}[2,68]$ beams, all of them aiming at the synthesis of neutron-rich nuclides along the $N=126$ shell closure.

\section{Experimental details}

The SHIP velocity filter and its detection system were already described in previous articles $[22,23,69,70]$. Here, we present an overview of the important aspects of the experiment, which were necessary for this specific measurement. The experimental investigation of the reaction ${ }^{48} \mathrm{Ca}+{ }^{238} \mathrm{U}$ was performed at the SHIP separator [70] in three different irradiation periods which took already place in the years 2005-2007. The main focus was on the synthesis of superheavy nuclei with $Z=112$ in fusion-evaporation reactions. The first part of the investigations was in 2005 from April 6 to June 19, the second part was in 2006 from October 4 to 30 and the third part was in the year 2007 from January 19 to February 14. A summary of the beam time along with the key parameters of the experiments are presented in the Table 1 of the article [70]. The here presented results on MNT reactions were measured in the middle of the fusion experiments. For this, the SHIP fields were set for $7.7 \mathrm{~h}$ to transmit target-like transfer products moving in forward angles of $(0 \pm 2)$ degree. The beam energy of $235.2 \mathrm{MeV}$ delivered from the UNILAC accelerator was continued as it was set for the fusion evaporation study. The beam energy at the center of the target is estimated to be $233.3 \mathrm{MeV}$, which is close to the Bass interaction barrier of $232.9 \mathrm{MeV}$ [71]. After this, again the fusion setting was continued for another $199 \mathrm{~h}$. In this case, the direct passage of target-like transfer products is suppressed by a factor of 1000 . This was a very favourable condition to record the residual long-living $\alpha$ and $\gamma$ decay activities of the already implanted vast amount of target-like MNT products in the silicon detector with half-lives from few hours to several days.

The average intensity of the ${ }^{48} \mathrm{Ca}$ beam was $2.6 \times 10^{12}$ particles/s with a total number of $7.16 \times 10^{16}$ projectiles in $7.7 \mathrm{~h}$ irradiation time. We used metallic uranium targets with an average thickness of $302 \mu \mathrm{g} / \mathrm{cm}^{2}$ which were deposited on $42 \mu \mathrm{g} / \mathrm{cm}^{2}$ thick carbon backing foils and covered with carbon layers with a thickness of $10 \mu \mathrm{g} / \mathrm{cm}^{2}$ and in some cases $20 \mu \mathrm{g} / \mathrm{cm}^{2}$. The lowest accessible life-times of $20 \mu \mathrm{s}$ were given by the conversion time plus the dead time of the data acquisition system.

SHIP accepts only reaction products which are emitted to forward angles of $(0 \pm 2)$ degrees. MNT reaction products produced in deep inelastic collisions around the Coulomb barrier energy have very wide angular distributions. Experimental data for the angular acceptance of SHIP for MNT products are not available. Therefore, we rely on the efficiencies obtained from calculations in the di-nuclear system model [72] for our collision system and beam energy. The respective value is about $0.5 \%$ for reactions of ${ }^{48} \mathrm{Ca}+{ }^{238} \mathrm{U}$. Uncertainties of a factor 5 to 10 might be possible. 


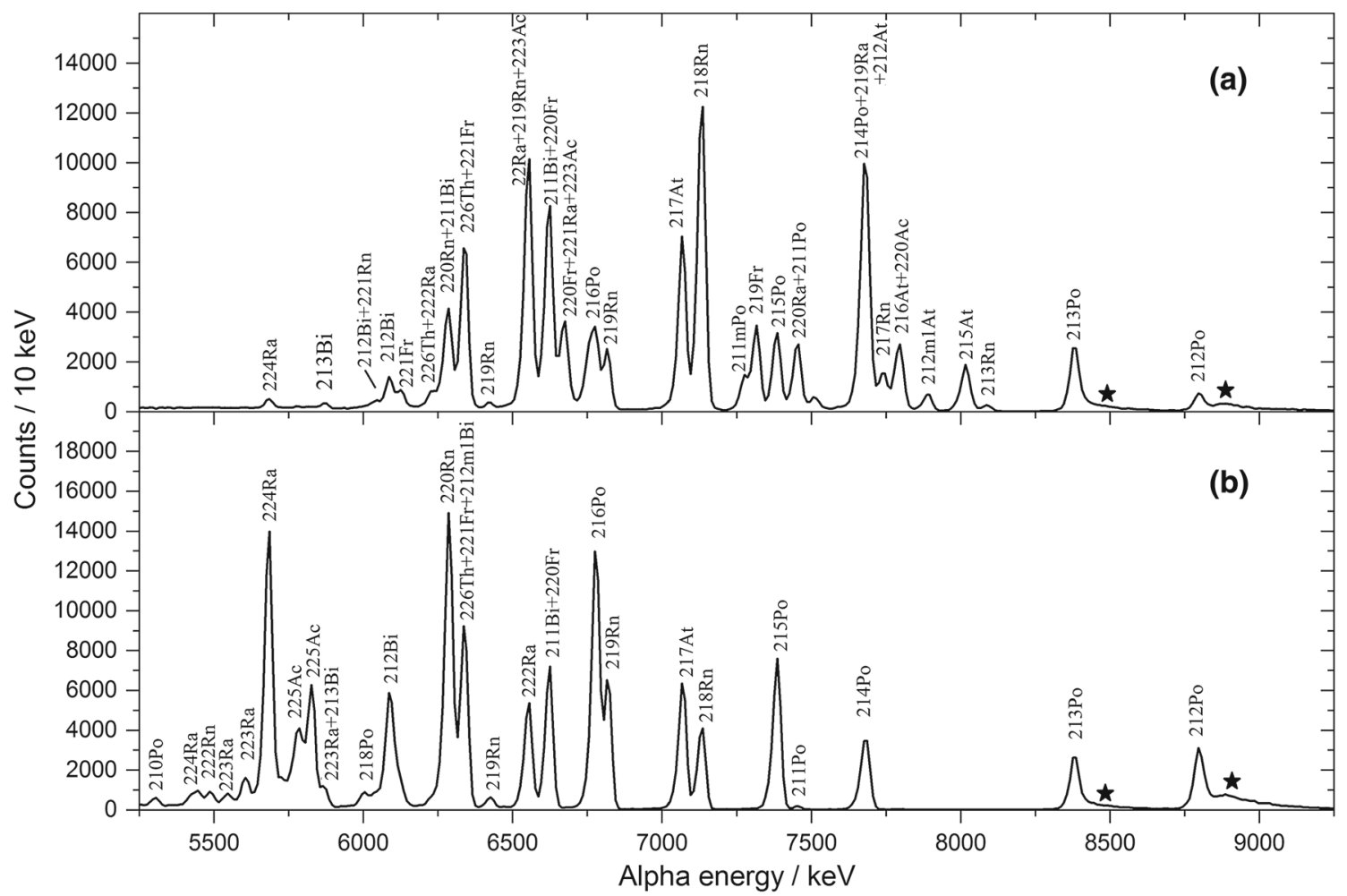

Fig. 1 Measured $\alpha$ spectra of the target-like transfer products from the ${ }^{48} \mathrm{Ca}+{ }^{238} \mathrm{U}$ reaction. a Spectrum accumulated during the $7.7 \mathrm{~h}$ measurement of transfer reaction products. b Spectrum accumulated during the $199 \mathrm{~h}$ of SHIP settings for fusion-evaporation residues which was

\section{Results of the ${ }^{48} \mathrm{Ca}+{ }^{238} \mathrm{U}$ experiment}

\subsection{Isotopic distributions and cross-sections}

The isotope identification in the present work is mainly associated with the $\alpha, \gamma$ and SF decay properties of the populated nuclei. The literature data for the decay energy, half-lives and branching ratios were taken from [73]. Within our measurement time, $\alpha$ and $\gamma$ spectra were accumulated for the strongly populated nuclides with half-lives up to few hours. Both, the $\alpha$ and $\gamma$ spectra shown in Figs. 1 and 2 are measured during the beam-off condition which was given by the pulse structure of the UNILAC beam. It consisted of $5 \mathrm{~ms}$ long beam pulses followed by $15 \mathrm{~ms}$ long beam-off periods. In Fig. 1a the $\alpha$-decay spectrum of the populated candidates during the $7.7 \mathrm{~h}$ setting for transfer products is presented. The other Fig. 1b includes the $\alpha$ decays from Fig. 1a and those decays which occurred up to $199 \mathrm{~h}$ after the transfer setting. It shows therefore mainly the long-lived MNT products with half-lives up to few days. The $\alpha$ lines in Fig. 1b belong mainly to the members of the $\alpha$-decay chains originating from the parent nuclei ${ }^{226} \mathrm{Ac}\left(T_{1 / 2}=29.37 \mathrm{~h}\right),{ }^{230} \mathrm{U}$ (20.8d), ${ }^{225} \mathrm{Ac}(9.92 \mathrm{~d}),{ }^{223} \mathrm{Ra}(11.43 \mathrm{~d}),{ }^{224} \mathrm{Ra}(3.66 \mathrm{~d})$ and following the transfer setting. The tails (asterisk) towards higher $\alpha$ energies are due to the pileup of $\beta^{-}$particles emitted from ${ }^{212} \mathrm{Bi}$ and ${ }^{213} \mathrm{Bi}$ isotopes with the $\alpha$ energies of the short-living ${ }^{212} \mathrm{Po}\left(\mathrm{T}_{1 / 2}=0.3 \mu \mathrm{s}\right)$ and ${ }^{213} \mathrm{Po}\left(\mathrm{T}_{1 / 2}=4.2 \mu \mathrm{s}\right)$ daughter nuclei. For details see text

${ }^{222} \mathrm{Rn}(3.82 \mathrm{~d})$. The daughter nuclei of the decay chains have half-lives from few seconds down to microseconds. The $\alpha$ $\alpha$ correlation technique allowed us to attribute these $\alpha$-lines. Some of the $\alpha$-lines of directly populated nuclei and of nuclei which are strongly populated by $\beta$-decays of their parents, are also attributed easily. These lines mainly belong to the isotopes ${ }^{210-213} \mathrm{Po}$ and ${ }^{211,212,212 m} \mathrm{Bi}$. Most of the shortliving rarely populated nuclei (not visible in Fig. 1) with half-lives up to few hundred milliseconds were identified by correlating the recoil and subsequent $\alpha$ 's. The $\gamma$-spectra measured during the transfer setting and the following $199 \mathrm{~h}$ of fusion-evaporation settings are shown in Fig. 2. The lowest cross-section reached for $\alpha$ emitters was $20 \mathrm{pb} / \mathrm{sr}$. For isotope identification by $\gamma$ rays it was $150 \mathrm{nb} / \mathrm{sr}$. These limits are differential cross-sections related to the acceptance angle of SHIP. Assuming the SHIP angular efficiency of $0.5 \%$, the total cross-section limit was $4 \mathrm{nb}$ for $\alpha$ emitters and $30 \mu \mathrm{b}$ for isotope identification via $\gamma$ rays.

Figure 3 shows the region of identified nuclides in the nuclide chart. The filled boxes without circles are the identified nuclides by following the recoil- $\alpha$ and $\alpha-\alpha$ correlations of the implanted nuclides in the silicon detector. The ones indicated by filled circles are the identified nuclei using the 


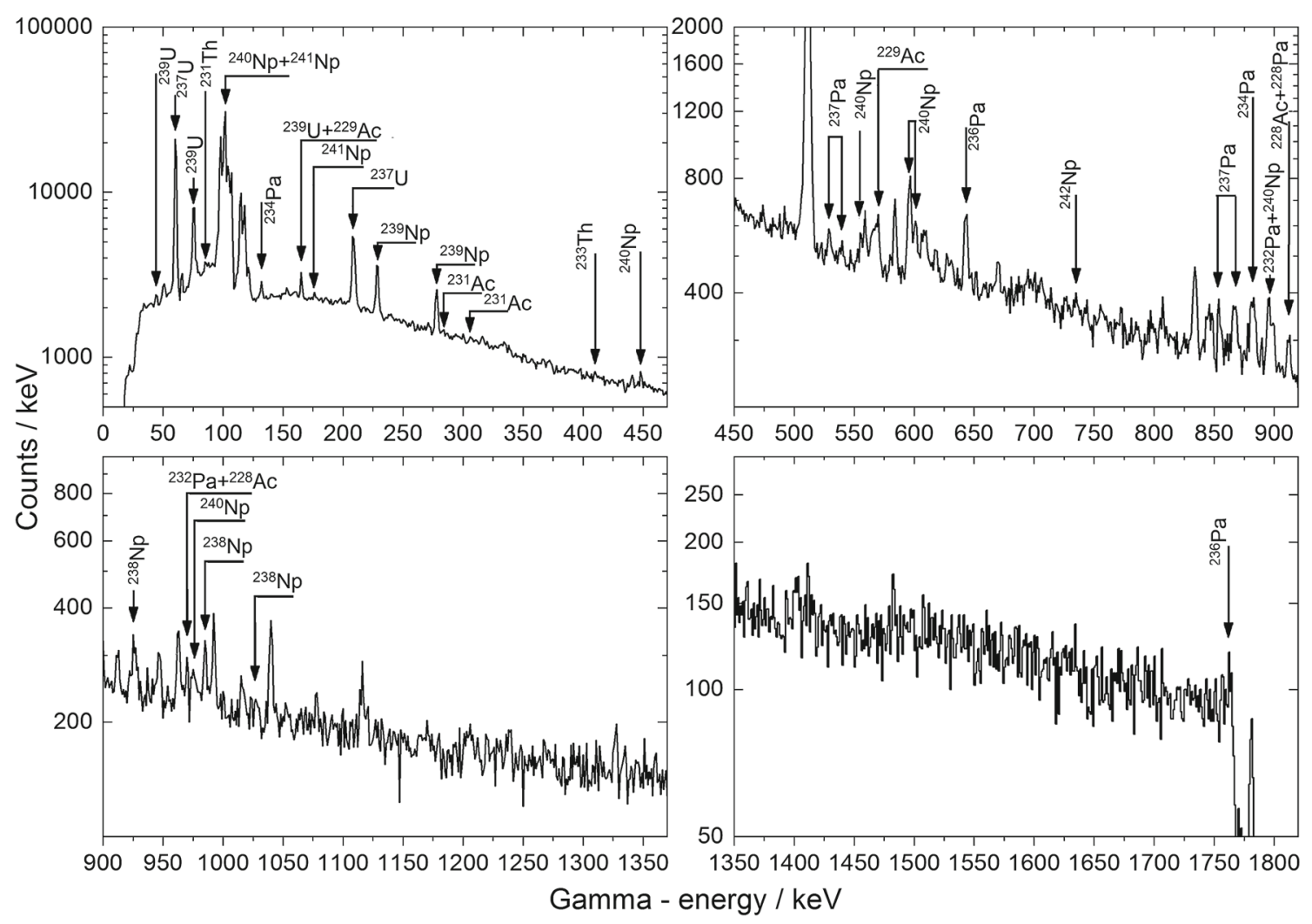

Fig. $2 \gamma$-spectra accumulated during the $7.7 \mathrm{~h} \mathrm{SHIP} \mathrm{settings} \mathrm{for} \mathrm{transfer} \mathrm{products} \mathrm{and} \mathrm{the} \mathrm{following} 199 \mathrm{~h}$ with settings for fusion-evaporation residues. Some of the unassigned lines are still uncertain

Fig. 3 The nuclear chart showing the region of identified nuclides from the reaction ${ }^{48} \mathrm{Ca}+{ }^{238} \mathrm{U}$. The filled boxes without circles represent isotopes which were identified using $\alpha$ decay. Isotopes indicated by filled circles were identified by their $\gamma$ decay properties. The three americium fission isomers with half-lives up to $14 \mathrm{~ms}$ were identified by following the recoil-spontaneous-fission correlations

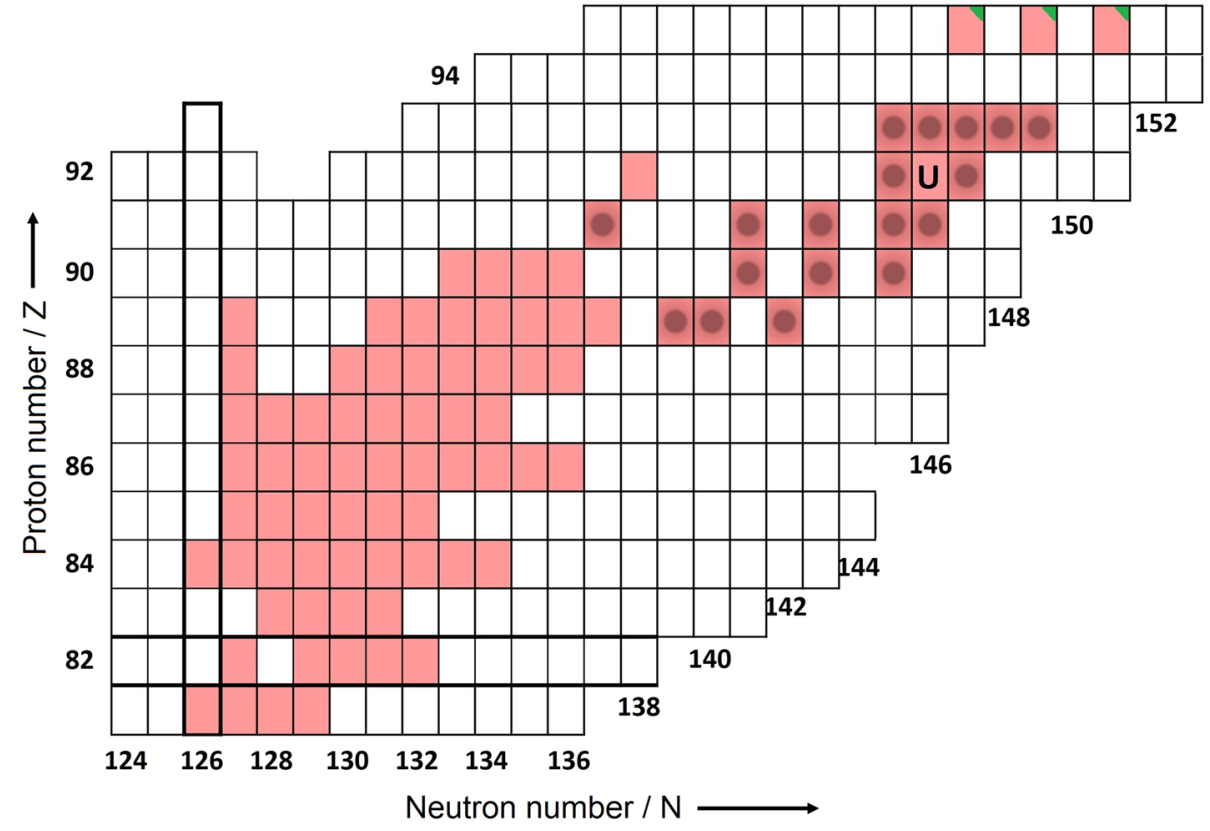




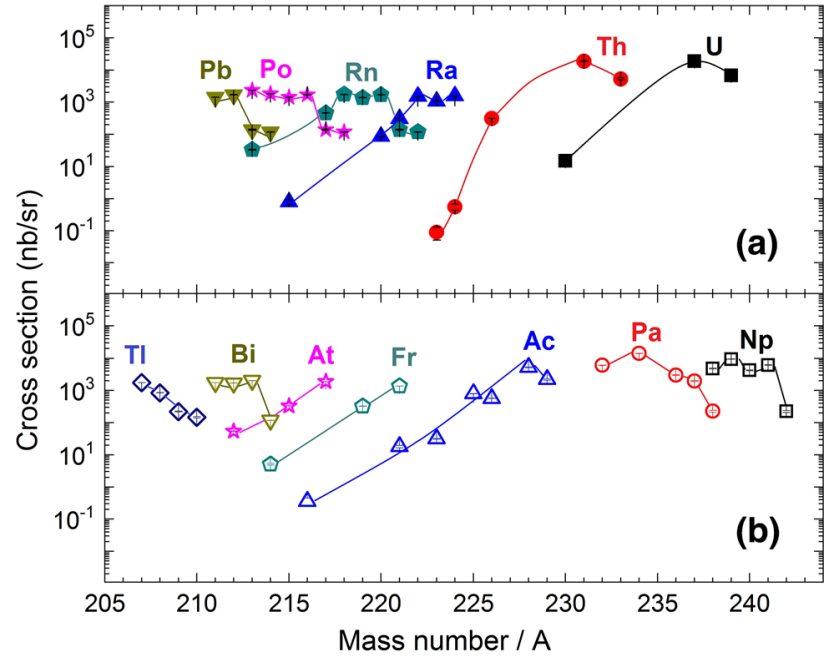

Fig. 4 Production cross-sections as a function of mass number A estimated from the cumulative yields of the identified target-like transfer products in the ${ }^{48} \mathrm{Ca}+{ }^{238} \mathrm{U}$ reaction. The upper figure shows isotopic distributions for even-Z nuclei (a); the lower figure is for odd- $Z$ nuclei (b). Error bars represent statistical errors. The lines are used to guide the eye

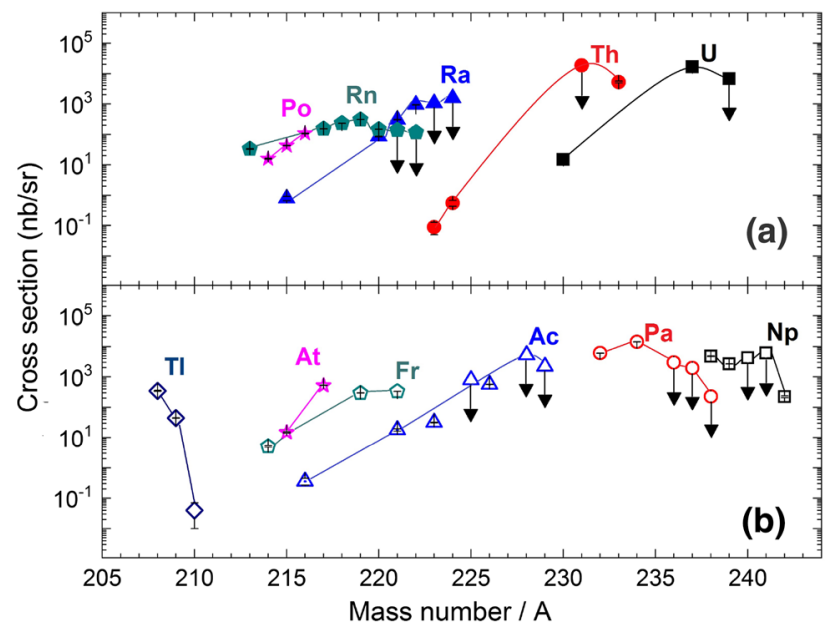

Fig. 5 Production cross-sections as a function of mass number A of the directly populated target-like transfer products in the ${ }^{48} \mathrm{Ca}+{ }^{238} \mathrm{U}$ reaction. The arrows indicate upper limit cross-sections for nuclei with small contributions from parent decays which could not be resolved from the direct production cross-section. The upper figure shows isotopic distributions for even- $\mathrm{Z}$ nuclei (a); the lower figure is for odd- $\mathrm{Z}$ nuclei (b). Error bars represent statistical errors. The lines are used to guide the eye

$\gamma$-decay properties. Three short-living isotopes of americium fission isomers with half-lives up to $14 \mathrm{~ms}$ were identified by analysing the recoil-SF correlations. The experimental crosssections of target-like MNT products of individual elements as a function of mass number of the identified isotopes are shown in Fig. 4. The estimated errors represent the statistical uncertainties. The even and odd elements are shown separately. The given cross-sections are cumulative cross- sections. It means they contain directly populated nuclei as well as nuclei populated by precursor decays. In Fig. 5 we present the cross-section versus mass number A for the directly populated isotopes. Some of the strongly and directly populated nuclides have some minor contributions from the decay of other nuclides. In cases where we could not determine these contributions we indicated the cross-sections as upper limit values. The cumulative and direct cross-sections of individual isotopes are listed in Table 1. In the region below $\mathrm{Pb}$, only isotopes of thallium $(Z=81)$ could be identify in our experiment. The measured lowest cross-section was $70 \mu \mathrm{b}$ for the isotope ${ }^{208} \mathrm{Tl}$. The detection of nuclei with smaller $\mathrm{Z}$ was prevented by the sensitivity limit of $30 \mu \mathrm{b}$ for $\beta$ emitters.

\subsection{Excitation energy and total kinetic energy of the MNT products}

The total kinetic energy (TKE) of the MNT products we calculated from the velocity of the detected target-like nucleus and by assuming a binary reaction process like described in our earlier publication [22]. Figure 6 shows the calculated values of TKE (open squares) as a function of $\mathrm{Z}$ of the target-like MNT products of elements Po, Rn, Fr and Ra. For comparison we show in Fig. 6 also the expected Viola energies which we calculated according to [74]. The Viola energy is the total kinetic energy of two fission fragments which are emitted from a compound system in thermal equilibrium. The increase of TKE towards smaller $\mathrm{Z}$ of the target-like MNT product is dominated by the increasing charge symmetry of projectile-like and target-like fragment which increases the Coulomb repulsion between them. We observe that the experimental TKE values are about 25 $\mathrm{MeV}$ lower than the Viola energy which confirms the deep inelastic nature of the underlying process. In this case, the system has "forgotten" the entrance channel kinematics and the TKE of the exit channel fragments is determined by the Coulomb repulsion between of projectile-like and target-like MNT product. The observation that the experimental TKE values are even below the Viola energy indicates a strong deformation of the MNT products at their scission point. We made this observation also in other systems $[18,22]$.

The sum of excitation energies of the projectile-like and target-like MNT product, $\mathrm{E}_{P L}^{*}+\mathrm{E}_{T L}^{*}$, is determined by the TKE and the centre-of-mass energy $\mathrm{E}_{C M}$ according to the following equation:

$E_{P L}^{*}+E_{T L}^{*}=E^{*} \leq E_{C M}-T K E$

The dissipated energy is also contributing to other degrees of freedom like deformation of the nuclei hence the value of $E^{*}$ in eq. (1) represents the upper limit. Neglecting shell effects in systems approaching equilibrium, like indicated 
Table 1 Cross-sections of directly populated MNT products $\left(\sigma_{D C}\right)$ and cumulative cross-sections $\left(\sigma_{C C}\right)$ of the observed MNT products from collisions of ${ }^{48} \mathrm{Ca}+{ }^{238} \mathrm{U}$. The cross-sections are differential crosssections related to the SHIP acceptance angle of $(0 \pm 2)$ degrees. Error bars represent statistical errors

\begin{tabular}{|c|c|c|c|c|c|}
\hline El. & $\mathrm{Z}$ & $\mathrm{N}$ & $\mathrm{A}$ & $\sigma_{D C}(\mathrm{nb} / \mathrm{sr})$ & $\sigma_{C C}(\mathrm{nb} / \mathrm{sr})$ \\
\hline \multirow[t]{4}{*}{$\mathrm{Tl}$} & \multirow[t]{4}{*}{81} & 126 & 207 & - & $1747 \pm 7$ \\
\hline & & 127 & 208 & $348 \pm 12$ & $851 \pm 4$ \\
\hline & & 128 & 209 & $45 \pm 0.9$ & $221 \pm 7$ \\
\hline & & 129 & 210 & $0.04 \pm 0.03$ & $146 \pm 6$ \\
\hline \multirow[t]{4}{*}{$\mathrm{Pb}$} & \multirow[t]{4}{*}{82} & 129 & 211 & - & $1421 \pm 9$ \\
\hline & & 130 & 212 & - & $1702 \pm 6$ \\
\hline & & 131 & 213 & - & $139 \pm 4$ \\
\hline & & 132 & 214 & - & $118 \pm 2$ \\
\hline \multirow[t]{4}{*}{$\mathrm{Bi}$} & \multirow[t]{4}{*}{83} & 128 & 211 & - & $1752 \pm 8$ \\
\hline & & 129 & 212 & - & $1702 \pm 6$ \\
\hline & & 130 & 213 & - & $2031 \pm 8$ \\
\hline & & 131 & 214 & - & $118 \pm 2$ \\
\hline \multirow[t]{6}{*}{ Po } & \multirow[t]{6}{*}{84} & 129 & 213 & - & $2350 \pm 9$ \\
\hline & & 130 & 214 & $15.7 \pm 0.6$ & $1814 \pm 6$ \\
\hline & & 131 & 215 & $42.7 \pm 0.9$ & $1421 \pm 9$ \\
\hline & & 132 & 216 & $107 \pm 3$ & $1702 \pm 6$ \\
\hline & & 133 & 217 & - & $139 \pm 4$ \\
\hline & & 134 & 218 & - & $118 \pm 2$ \\
\hline \multirow[t]{3}{*}{ At } & \multirow[t]{3}{*}{85} & 128 & 213 & - & $54 \pm 1.2$ \\
\hline & & 130 & 215 & $14.8 \pm 0.6$ & $331 \pm 2$ \\
\hline & & 132 & 217 & $525.6 \pm 3.5$ & $1892 \pm 8$ \\
\hline \multirow[t]{7}{*}{$\mathrm{Rn}$} & \multirow[t]{7}{*}{86} & 127 & 213 & $33 \pm 0.9$ & $33 \pm 0.9$ \\
\hline & & 131 & 217 & $153 \pm 3$ & $458 \pm 5$ \\
\hline & & 132 & 218 & $231 \pm 2$ & $1745 \pm 6$ \\
\hline & & 133 & 219 & $307 \pm 3$ & $1378 \pm 9$ \\
\hline & & 134 & 220 & $148 \pm 2$ & $1702 \pm 6$ \\
\hline & & 135 & 221 & $\leq 139$ & $139 \pm 4$ \\
\hline & & 136 & 222 & $\leq 118$ & $118 \pm 2$ \\
\hline \multirow[t]{3}{*}{$\mathrm{Fr}$} & \multirow[t]{3}{*}{87} & 127 & 214 & $5 \pm 0.3$ & $5 \pm 0.3$ \\
\hline & & 132 & 219 & $294 \pm 3$ & $326 \pm 3$ \\
\hline & & 134 & 221 & $335 \pm 2$ & $1366 \pm 7$ \\
\hline \multirow[t]{6}{*}{$\mathrm{Ra}$} & \multirow[t]{6}{*}{88} & 127 & 215 & $0.8 \pm 0.1$ & $0.8 \pm 0.1$ \\
\hline & & 132 & 220 & $85.4 \pm 2.3$ & $85.4 \pm 2.3$ \\
\hline & & 133 & 221 & $305 \pm 4$ & $305 \pm 4$ \\
\hline & & 134 & 222 & $944 \pm 4$ & $1513 \pm 6$ \\
\hline & & 135 & 223 & $\leq 1071$ & $1071 \pm 9$ \\
\hline & & 136 & 224 & $\leq 1554$ & $1554 \pm 6$ \\
\hline \multirow[t]{7}{*}{ Ac } & \multirow[t]{7}{*}{89} & 127 & 216 & $0.36 \pm 0.09$ & $0.36 \pm 0.09$ \\
\hline & & 132 & 221 & $18.0 \pm 1.4$ & $18.0 \pm 1.4$ \\
\hline & & 134 & 223 & $31.3 \pm 0.87$ & $31.3 \pm 0.87$ \\
\hline & & 136 & 225 & $\leq 796$ & $796 \pm 7$ \\
\hline & & 137 & 226 & $570 \pm 4$ & $570 \pm 4$ \\
\hline & & 139 & 228 & $\leq 5235$ & $5235 \pm 136$ \\
\hline & & 140 & 229 & $\leq 2192$ & $2192 \pm 117$ \\
\hline
\end{tabular}

Table 1 continued

\begin{tabular}{|c|c|c|c|c|c|}
\hline El. & $\mathrm{Z}$ & $\mathrm{N}$ & A & $\sigma_{D C}(\mathrm{nb} / \mathrm{sr})$ & $\sigma_{C C}(\mathrm{nb} / \mathrm{sr})$ \\
\hline \multirow[t]{5}{*}{ Th } & \multirow[t]{5}{*}{90} & 133 & 223 & $0.09 \pm 0.04$ & $0.09 \pm 0.04$ \\
\hline & & 134 & 224 & $0.56 \pm 0.12$ & $0.56 \pm 0.12$ \\
\hline & & 136 & 226 & - & $311 \pm 2$ \\
\hline & & 141 & 231 & $\leq 18716$ & $18716 \pm 241$ \\
\hline & & 143 & 233 & $5285 \pm 374$ & $5285 \pm 374$ \\
\hline \multirow[t]{5}{*}{$\mathrm{Pa}$} & \multirow[t]{5}{*}{91} & 141 & 232 & $6097 \pm 75$ & $6097 \pm 75$ \\
\hline & & 143 & 234 & $14145 \pm 112$ & $14145 \pm 112$ \\
\hline & & 145 & 236 & $\leq 2999$ & $2999 \pm 62$ \\
\hline & & 146 & 237 & $\leq 1970$ & $1970 \pm 71$ \\
\hline & & 147 & 238 & $\leq 227$ & $227 \pm 15$ \\
\hline \multirow[t]{3}{*}{$\mathrm{U}$} & \multirow[t]{3}{*}{92} & 138 & 230 & $15 \pm 1$ & $15 \pm 1$ \\
\hline & & 145 & 237 & $16572 \pm 127$ & $18542 \pm 142$ \\
\hline & & 147 & 239 & $\leq 6737$ & $6737 \pm 54$ \\
\hline \multirow[t]{5}{*}{$\mathrm{Np}$} & \multirow[t]{5}{*}{93} & 145 & 238 & $4810 \pm 133$ & $4810 \pm 133$ \\
\hline & & 146 & 239 & $2701 \pm 38$ & $9438 \pm 133$ \\
\hline & & 147 & 240 & $\leq 4240$ & $4240 \pm 115$ \\
\hline & & 148 & 241 & $\leq 6166$ & $6166 \pm 186$ \\
\hline & & 149 & 242 & $223 \pm 15$ & $223 \pm 15$ \\
\hline
\end{tabular}

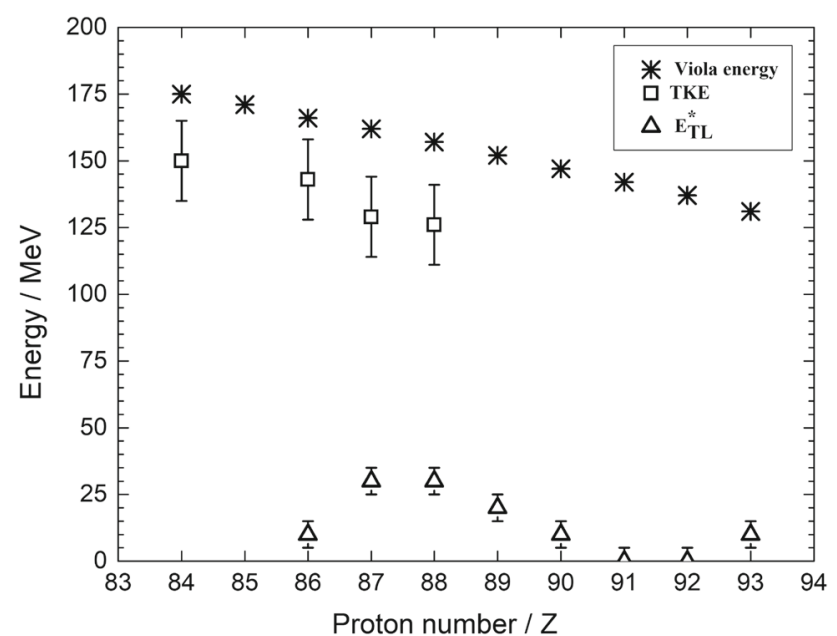

Fig. 6 Total kinetic energy TKE (squares) and excitation energy $\mathrm{E}_{T L}^{*}$ (triangles) of target-like transfer products as a function of the proton number $\mathrm{Z}$ of the transfer product. The measurement is from ${ }^{48} \mathrm{Ca}+{ }^{238} \mathrm{U}$ collisions at $233.3 \mathrm{MeV}$ beam energy. The error bars are related to the uncertainty given by the SHIP velocity acceptance at a given setting. For comparison, also the expected Viola energies [74] for fragments from the fissioning compound nucleus ${ }^{286} \mathrm{Cn}$ are given (asterisks)

by our small observed TKE values, $\mathrm{E}^{*}$ would be distributed between projectile-like and target-like MNT products linearly to their mass numbers $\mathrm{A}_{P L}$ and $\mathrm{A}_{T L}$. This results from the linear increase of the level densities with mass number in the liquid drop model. However, the results of the $\mathrm{Ca}+\mathrm{U}$ data indicate that shell effects cannot be neglected. Therefore, we used another method to derive $\mathrm{E}_{P L}^{*}$ and $\mathrm{E}_{T L}^{*}$, which 


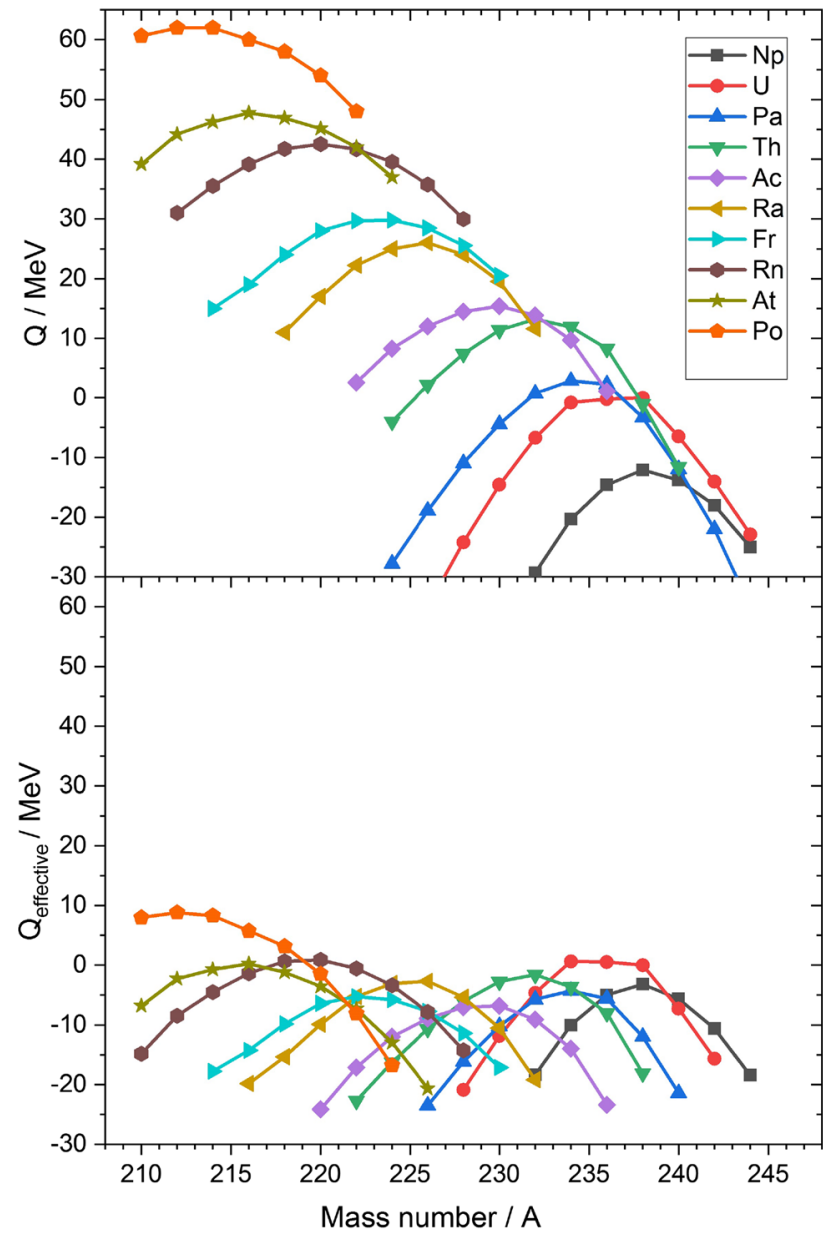

Fig. 7 Reaction Q value (upper fig.) and effective Q value (lower fig.) as a function of mass number of the primary MNT products are presented

Table 2 Column 1: Isotopes in the maxima of the expected primary isotopic distributions of target-like transfer products. column 2: Isotopes in the maxima of the measured secondary isotopic distributions of target-like transfer products from collisions of ${ }^{48} \mathrm{Ca}+{ }^{238} \mathrm{U}$ (see Fig. 5). column 3: Difference of the neutron numbers $\Delta \mathrm{N}$ between the primary and secondary transfer products from columns 1 and 2, which indicates the shift between primary and secondary isotopic distributions. column 4: Excitation energies of the target-like transfer products deduced from $\Delta \mathrm{N}$

\begin{tabular}{llll}
\hline $\begin{array}{l}\text { Primary } \\
\text { MNT product }\end{array}$ & $\begin{array}{l}\text { Secondary } \\
\text { MNT product }\end{array}$ & $\Delta \mathrm{N}$ & $\begin{array}{l}\mathrm{E}^{*} \\
{[\mathrm{MeV}]}\end{array}$ \\
\hline${ }^{238} \mathrm{~Np}$ & ${ }^{237} \mathrm{~Np}$ & 1 & 10 \\
${ }^{236} \mathrm{U}$ & ${ }^{237} \mathrm{U}$ & - & 0 \\
${ }^{234} \mathrm{~Pa}$ & ${ }^{234} \mathrm{~Pa}$ & 0 & 0 \\
${ }^{232} \mathrm{Th}$ & ${ }^{231} \mathrm{Th}$ & 1 & 10 \\
${ }^{230} \mathrm{Ac}$ & ${ }^{228} \mathrm{Ac}$ & 2 & 20 \\
${ }^{226} \mathrm{Ra}$ & ${ }^{223} \mathrm{Ra}$ & 3 & 30 \\
${ }^{223} \mathrm{Fr}$ & ${ }^{220} \mathrm{Fr}$ & 3 & 30 \\
${ }^{220} \mathrm{Rn}$ & ${ }^{219} \mathrm{Rn}$ & 1 & 10 \\
\hline
\end{tabular}

we described already in a previous publication [18]. In this approach we compared the measured isotopic distributions of secondary MNT products (after de-excitation) in Fig. 5 with the expected isotopic distributions of the primary transfer products (before the de-excitation). For this we assume that the yields of primary transfer products are strongly influenced by the effective reaction Q-value $\left(\mathrm{Q}_{e f f}\right)$ [75], which depends on the reaction Q-value and the differences between Coulomb barrier in entrance $\left(\mathrm{V}_{c . i}\right)$ and exit $\left(\mathrm{V}_{c . f}\right)$ channel, and is expressed by the following equation:

$Q_{e f f}=Q+V_{c . i}-V_{c . f}$
$Q_{e f f}=Q+\frac{1.44 Z_{1} Z_{2}}{1.2\left[A_{1}^{1 / 3}+A_{2}^{1 / 3}\right]}-\frac{1.44 Z_{3} Z_{4}}{1.2\left[A_{3}^{1 / 3}+A_{4}^{1 / 3}\right]}$

where $A_{1}\left(Z_{1}\right)$ and $A_{2}\left(Z_{2}\right)$ are the mass (atomic) numbers of projectile and target in the entrance channel and $A_{3}\left(Z_{3}\right)$ and $\mathrm{A}_{4}\left(\mathrm{Z}_{4}\right)$ are the mass (atomic) numbers of projectile-like and target-like primary transferred products in the exit channel respectively. With

$Q=\left(M_{1}+M_{2}-M_{3}-M_{4}\right) c^{2}$

where $M_{1}\left(M_{2}\right)$ is the ground state mass of the projectile (target) and $M_{3}\left(M_{4}\right)$ is the ground state mass of the projectilelike (target-like) primary MNT products respectively.

Figure 7 represents the distributions of $\mathrm{Q}$ and $\mathrm{Q}_{\text {eff }}$ as a function of mass number of the primary transfer products. The Q-values according to equ. 4 are continuously increasing toward smaller proton number of the target-like MNT products which results from their increasing binding energy or decreasing mass, respectively. The effect becomes most pronounced if we approach the $\mathrm{Pb}$ valley. The increase of $\mathrm{Q}_{\text {eff }}$ values toward the $\mathrm{Pb}$ valley, is much smoother because the exit channel Coulomb barrier becomes larger with increasing mass (charge) symmetry of the system. For a given proton number those isotopes are preferably populated for which the reaction $\mathrm{Q}_{e f f}$-value has a maximum. The isotopes where the $\mathrm{Q}_{e f f}$-values have a maximum are expected as the most probable primary products. The difference $\Delta \mathrm{N}$ between the neutron number where the $\mathrm{Q}_{e f f}$-value distribution has a maximum and the neutron number where the measured distribution has a maximum reflects the average number of evaporated neutrons from the primary products. From the value of $\Delta \mathrm{N}$ we estimated the excitation energy of the nuclei. The neutron separation energies for nuclei in this mass region are 7 to $8 \mathrm{MeV}$ [73] and the kinetic energy of a neutron in the nucleus is $1.7 \mathrm{MeV}$ (energy at the maximum of the Boltzmann distribution). Therefore one can assume that about 10 $\mathrm{MeV}$ are required for the evaporation of one neutron and the excitation energy is given by $\mathrm{E}^{*}=\Delta \mathrm{N} \times 10 \mathrm{MeV}$. This method gives a direct information about the excitation energies of the primary target-like MNT products. 


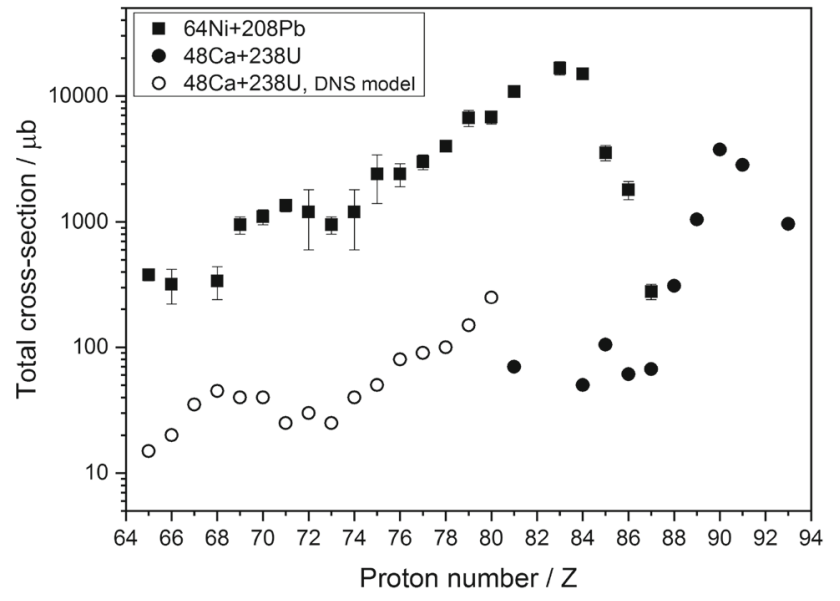

Fig. 8 Maximum cross-sections of multi-nucleon transfer products as a function of their proton number $\mathrm{Z}$. The given cross-sections correspond to the maxima of the respective isotopic distributions. filled circles: experimental cross-sections from collisions of ${ }^{48} \mathrm{Ca}+{ }^{238} \mathrm{U}$ (this work), open circles: DNS model calculations for ${ }^{48} \mathrm{Ca}+{ }^{238} \mathrm{U}$ [29], filled squares: experimental cross-sections from collisions of ${ }^{64} \mathrm{Ni}+{ }^{208} \mathrm{~Pb}$ [63]

The resulting values of $\mathrm{E}^{*}$ are shown in Table 2 and in Fig. 6 (open triangles). A pronounced structure is revealed where $\mathrm{E}^{*}$ adopts maximum values of $\approx 30 \mathrm{MeV}$ for isotopes of $\mathrm{Fr}, \mathrm{Ra}$ and $\mathrm{Ac}(Z=87-89)$. Elements close to the target nucleus $U$ have smaller excitation energies of $<10 \mathrm{MeV}$. These nuclei are usually not produced in deep inelastic processes where all kinetic energy dissipates, therefore less energy is available for excitation. A drop of excitation energies to values $<10 \mathrm{MeV}$ is also observed for elements below Fr. These nuclei are already located in the " $\mathrm{Pb}$ valley" and it is very likely that the double shell closure at $Z=82, N=126$ is the reason for their low excitation energies. In these cases, the projectile-like complementary nucleus must overtake the higher excitation energy.

\subsection{Comparison of the $\mathrm{Ca}+\mathrm{U}$ data with model calculations} and with experimental data from other collision systems

In this section we are going to compare measured and calculated isotopic distributions of MNT products from different collision systems. The collision systems for which experimental data are available are listed in Table 3. Model calculations are available for reactions of ${ }^{48} \mathrm{Ca}+{ }^{238} \mathrm{U}$ [29] and ${ }^{136} \mathrm{Xe}+{ }^{208} \mathrm{~Pb}[37,39]$. The aim of this study is to get information if $\mathrm{Pb}$ or actinide targets are more profitable to reach neutron-rich MNT products. First, we show in Fig. 8 the maximum cross-sections which are reached in collisions of $\mathrm{Ca}+\mathrm{U}$ and $\mathrm{Ni}+\mathrm{Pb}$ for isotopes of a certain element. The denoted experimental cross-sections for $\mathrm{Ca}+\mathrm{U}$ correspond to the maxima of the isotopic distributions in Fig. 5 and belong to isotopes which are close to the stability valley.
The given theoretical cross-sections correspond to the maxima of the isotopic distributions shown in [29]. Our data did not reveal isotopes of elements below $Z=81$. Therefore we cannot directly compare them with the DNS model crosssections from [29], but one can see that the experimental values join the model calculations within less than one order of magnitude in the transition region around $Z=80$. It can be noticed in the figure that the experimental cross-sections for elements 81 to 87 are nearly constant. We presume that this is mainly caused by the $\mathrm{Pb}$ shell effects at $Z=82$, $N=126$ which create a deep valley in the potential energy surface. The nucleon flow follows the valley which leads to a preferred creation of $\mathrm{Pb}$-like transfer products. Shell effects which influence the nucleon flow in deep inelastic reactions were also revealed in earlier experimental and theoretical works (see e.g. $[34,76,77])$. Another effect which might contribute to the enhanced cross-sections in the $\mathrm{Pb}$ region is the high survivability of these nuclei against fission. This leads to smaller losses of $\mathrm{Pb}$-like primary transfer products compared to actinide nuclei which have lower fission barriers.

In the region below $\mathrm{Pb}$, the so far most comprehensive experimental data from MNT reactions with $\mathrm{Pb}$ targets are from [63] where collisions of ${ }^{64} \mathrm{Ni}+{ }^{208} \mathrm{~Pb}$ were investigated. The maximum cross-sections for each isotopic distribution from this work are also shown in Fig. 8. Due to the lack of experimental data from $\mathrm{Ca}+\mathrm{U}$ in this region we can compare the $\mathrm{Ni}+\mathrm{Pb}$ data only with model calculations. Since $\mathrm{Pb}$ is 10 protons closer to this region than $\mathrm{U}$, it is not surprising that about 50 times larger maximum cross-sections for MNT products with $Z<82$ are reached with $\mathrm{Pb}$ targets. The maximum cross-sections in $\mathrm{Ni}+\mathrm{Pb}$ and $\mathrm{Ca}+\mathrm{U}$ reactions drop moderately and with similar slope toward smaller $\mathrm{Z}$ of the MNT products. Roughly one can extract that in both cases the maximum cross-section decreases by a factor of 10 per eight protons which are moved from target to projectile.

Figure 8 reveals still another interesting structure. There is a peak in the experimental cross-sections around $Z=70$ and also the DNS model calculations reveal a peak around $Z=68$. It cannot be caused by shell closure effects because neither the target-like nor the complementary projectile-like nucleus have closed shells at the respective $\mathrm{Z}$ and N. However, it could be an effect of strong deformation of the transfer products at $Z=(68-70)$ for target-like and $Z=(44-42)$ for projectile-like nuclei. The smaller Coulomb interaction of strongly deformed nuclei with respect to the neighbouring elements reduces the potential energy of the DNS and creates a valley to which the system is preferably driven [72].

In Fig. 9 we show the $\mathrm{Z}$ versus $\mathrm{N}$ values of MNT products which are in the maxima of the isotopic distributions for reactions of ${ }^{48} \mathrm{Ca}+{ }^{238} \mathrm{U},{ }^{64} \mathrm{Ni}+{ }^{208} \mathrm{~Pb}[63]$ and ${ }^{136} \mathrm{Xe}+{ }^{208} \mathrm{~Pb}$ [64]. Also, we included experimental data from ${ }^{238} \mathrm{U}+{ }^{238} \mathrm{U}$ collisions from one of our previous experiments [78]. Since no or only few experimental data below $\mathrm{Pb}$ are available 
Table 3 The MNT reactions from which experimental data are available in the region below $\mathrm{Pb}$ (column 1), the respective beam energies are given in column 2. The beam energy with respect to the interaction barrier is given in column 3 . The range of elements in which MNT products were observed is given in column 4

\begin{tabular}{llll}
\hline Reactions & Energy $[\mathrm{MeV} / \mathrm{u}]$ & $\mathrm{E} / \mathrm{B}_{\text {int }}$ & Observed TL elements \\
\hline${ }^{64} \mathrm{Ni}+{ }^{208} \mathrm{~Pb}[63]$ & 5.5 & 1.08 & $Z=64-88$ \\
${ }^{64} \mathrm{Ni}+{ }^{207} \mathrm{~Pb} \mathrm{[19]}$ & 5.0 & 1.01 & $Z=76-89$ \\
${ }^{136} \mathrm{Xe}+{ }^{208} \mathrm{~Pb}[64]$ & 5.5 & 1.04 & $Z=70-88$ \\
${ }^{136} \mathrm{Xe}+{ }^{198} \mathrm{Pt} \mathrm{[66]}$ & 7.98 & 1.54 & $Z=50-80$ \\
${ }^{136} \mathrm{Xe}+{ }^{198} \mathrm{Pt}[65]$ & 5.6 & 1.08 & $Z=72-83$ \\
${ }^{48} \mathrm{Ca}+{ }^{238} \mathrm{U}$ (this work) & 4.86 & 1.00 & $Z=81-95$ \\
${ }^{48} \mathrm{Ca}+{ }^{248} \mathrm{Cm} \mathrm{[22,23]}$ & 5.63 & 1.05 & $Z=82-102$ \\
\hline
\end{tabular}

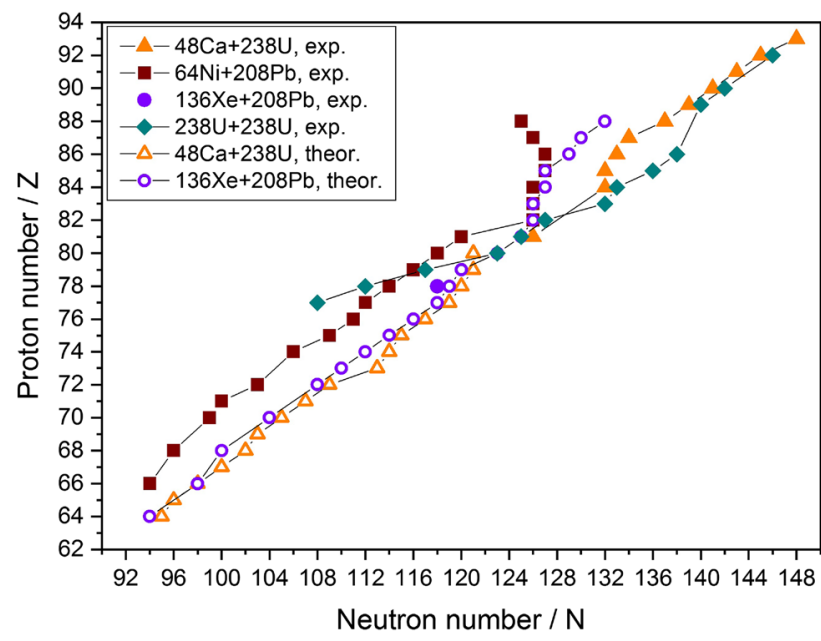

Fig. 9 Each data point denotes the location of an isotope distribution of (secondary) MNT products with element number $\mathrm{Z}$ on the neutron axis $\mathrm{N}$. The given $\mathrm{N}$ is the neutron number where the respective distribution has its maximum cross-section. Filled symbols represent experimental data from ${ }^{48} \mathrm{Ca}+{ }^{238} \mathrm{U}$ (this work), ${ }^{64} \mathrm{Ni}+{ }^{208} \mathrm{~Pb}[63],{ }^{136} \mathrm{Xe}+{ }^{208} \mathrm{~Pb}$ [64] and ${ }^{238} U+{ }^{238} U$ [78]. Open symbols represent model calculations for ${ }^{48} \mathrm{Ca}+{ }^{238} \mathrm{U}$ [29] and ${ }^{136} \mathrm{Xe}+{ }^{208} \mathrm{~Pb}$ [39]. Data points on the same curve belong to the same collision system. For example: the measured distribution of Pt isotopes $(Z=78)$ from MNT reactions of ${ }^{136} \mathrm{Xe}+$ ${ }^{208} \mathrm{~Pb}$ has the cross-section maximum at ${ }^{196} \mathrm{Pt}$, i.e. $N=118$

for $\mathrm{Ca}+\mathrm{U}$ and $\mathrm{Xe}+\mathrm{Pb}$, we show for these systems theoretical values. The representation in Fig. 9 reflects how far the isotopic distributions of the individual reaction systems are shifted toward the neutron-rich side. One can see that the isotope distributions from $\mathrm{Ca}+\mathrm{U}$ reach the largest neutron numbers, tightly followed by $\mathrm{Xe}+\mathrm{Pb}$. One can also see that the slope of all curves becomes flatter when they approach the $\mathrm{Pb}$-valley. We interpret this as influence of the $\mathrm{Pb}$ shells on the potential energy surface which leads to the effect that isotope distributions of elements close to $\mathrm{Pb}$ centre around $N=126$. In fact, it is the same reason which induces the small excitation energies and constant maximum cross-sections of $\mathrm{Pb}$ like fragments revealed by Figs. 6 and 8. Noteworthy is, that a slight flattening is even revealed for $\mathrm{U}+\mathrm{U}$ collisions which indicates that shell effects are still acting to a certain extent also in such heavy systems [78].
The above shown results reveal that $\mathrm{Pb}$ targets lead to about 50 times larger maximum cross-sections than $\mathrm{U}$ targets, but the isotope distributions from $\mathrm{U}$ targets are the most neutron-rich ones. They are tightly followed by the distributions from $\mathrm{Xe}+\mathrm{Pb}$, which have on average only two neutrons less. With $\mathrm{Ni}$ beams on $\mathrm{Pb}$ the distributions are much more neutron-deficient with a difference of 10 neutrons with respect to $\mathrm{Ca}+\mathrm{U}$ reactions.

In Fig. 10 we compare exemplary the isotope distributions for MNT products of $\operatorname{Pt}(Z=78), \operatorname{Re}(Z=75)$ and $\mathrm{Yb}(Z=70)$ measured in reactions of $\mathrm{Ni}+\mathrm{Pb}[63]$ and compare them with model calculations for $\mathrm{Ca}+\mathrm{U}$ [29] and with experimental (if available) [64] and theoretical data for $\mathrm{Xe}+\mathrm{Pb}$ [39]. It can be noticed that in $\mathrm{Ni}+\mathrm{Pb}$ collisions quite high cross-sections were measured also for isotopes quite far below $\mathrm{Pb}$ and that the maximum cross-sections decrease only slightly with proton number. However, the populated isotopes are more neutron-deficient compared to the other two reactions and it is indicated that for isotopes along the $N=126$ shell the cross-sections reach already the sub-picobarn scale, which makes them experimentally not accessible. It is also indicated that the (theoretical) cross-sections for $\mathrm{Ca}+\mathrm{U}$ overtake the ones of $\mathrm{Ni}+\mathrm{Pb}$ toward the neutron-rich side. For $\mathrm{Xe}$ beams on $\mathrm{Pb}$, the theoretical distributions and the experimental one which is available for Pt indicate wide and neutronrich distributions with higher cross-sections than $\mathrm{Ca}+\mathrm{U}$. But it is also revealed that toward smaller proton numbers the cross-sections in $\mathrm{Ca}+\mathrm{U}$ collisions come closer to the ones from $\mathrm{Xe}+\mathrm{Pb}$

\section{Fragmentation versus transfer reactions}

\subsection{Neutron-rich isotopes with $82 \leq Z \leq 92$}

Projectile fragmentation at relativistic energies together with effective separation and detection of the exotic fragments is so far a powerful method to populate wide regions of the nuclide chart up to uranium. At the GSI fragment separator (FRS) neutron-rich nuclides below uranium were successfully made in reactions of $1 \mathrm{GeV} / \mathrm{u}{ }^{238} \mathrm{U}(Z=92, N=146)$ 

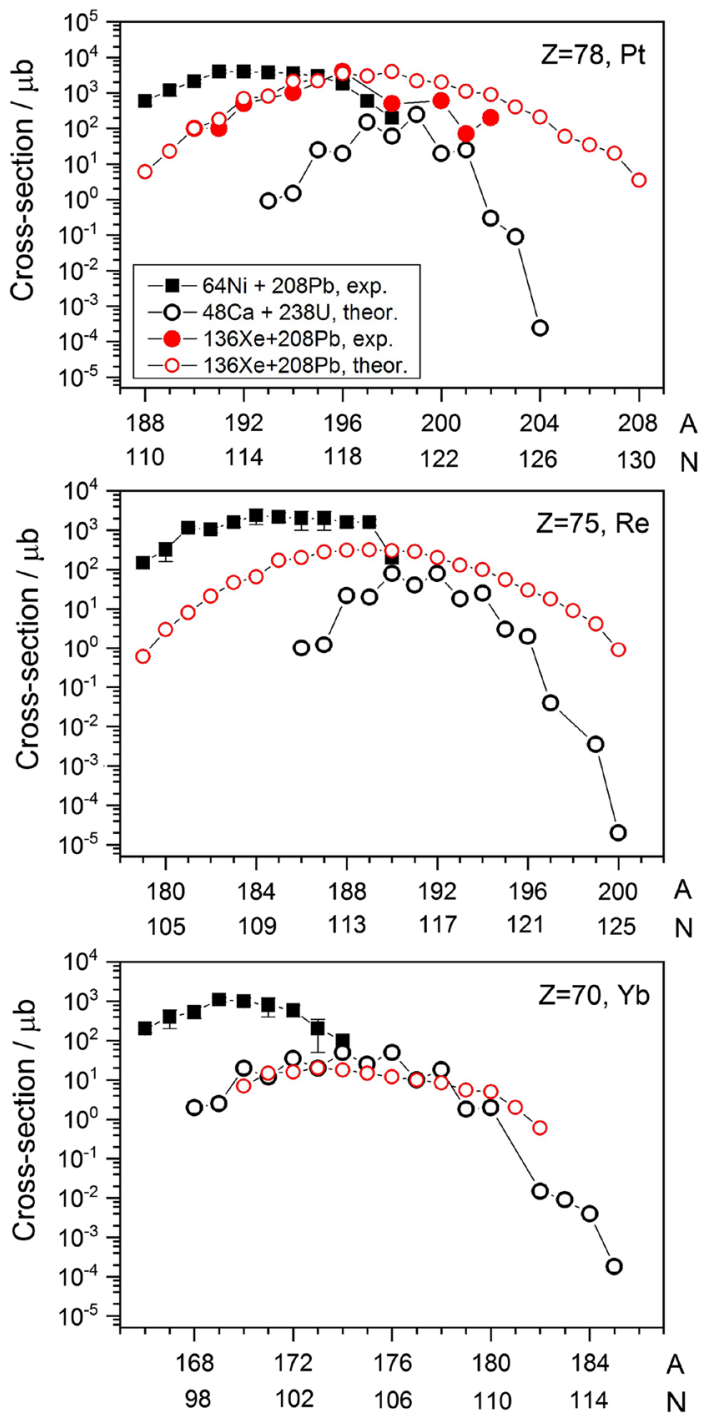

Fig. 10 Isotopic distributions of MNT products of elements $\mathrm{Pt}(Z=$ $78), \operatorname{Re}(Z=75)$ and $\mathrm{Yb}(Z=70)$. Filled squares: experimental data from ${ }^{64} \mathrm{Ni}+{ }^{208} \mathrm{~Pb}$ collisions [63], filled red circles: experimental data from ${ }^{136} \mathrm{Xe}+{ }^{208} \mathrm{~Pb}$ collisions [64], open red circles: model calculations for ${ }^{136} \mathrm{Xe}+{ }^{208} \mathrm{~Pb}$ [39], open black circles: model calculations for ${ }^{48} \mathrm{Ca}+$ ${ }^{238} \mathrm{U}[29]$

on beryllium targets [79] and in spallation-evaporation reactions of $1 \mathrm{GeV} / \mathrm{u}^{238} \mathrm{U}$ on proton target [68]. In the following we compare the capacity of fragmentation and transfer reactions for the production of neutron-rich isotopes below uranium.

In fragmentation reactions of ${ }^{238} \mathrm{U}$ beams, neutron-rich isotopes of elements down to francium $(Z=87)$ were observed having neutron numbers close to the neutron number of the primary beam [80]. Cross-sections are dropping dramatically for every proton removal along $N=146$ and reached a value of $\sim 1 \mathrm{nb}$ for ${ }^{233} \mathrm{Fr}$ [80]. The process is described as cold fragmentation because of the low fragment excitation energy, resulting in no evaporation of neutrons.

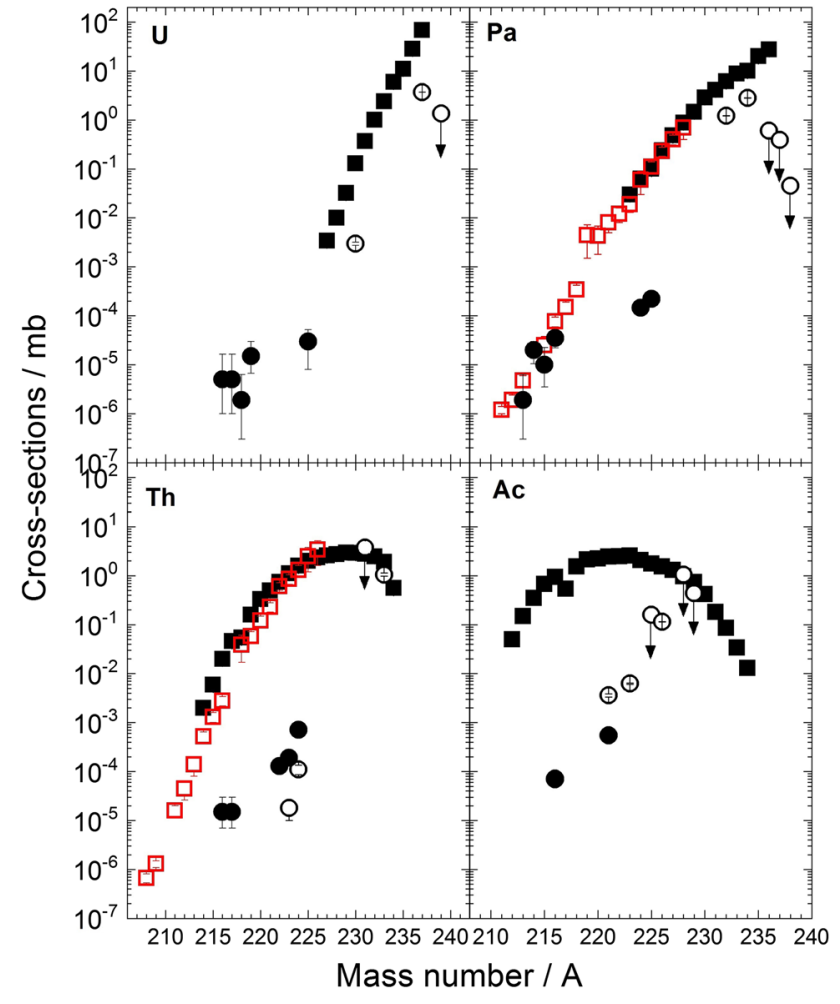

Fig. 11 The production cross-sections of uranium, protactinium, thorium and actinium transfer products from the ${ }^{48} \mathrm{Ca}+{ }^{238} \mathrm{U}$ reaction (open circles) and ${ }^{48} \mathrm{Ca}+{ }^{248} \mathrm{Cm}$ (solid circles) [22] are compared with the cross-sections from the spallation-evaporation reaction of ${ }^{238} \mathrm{U}$ ( $1 \mathrm{GeV} / \mathrm{u})+{ }^{1} \mathrm{H}$ (solid squares) [68]. The available fragmentation yields for protactinium and thorium (open squares) from $1 \mathrm{~A} \mathrm{GeV}^{238} \mathrm{U}$ on a beryllium target [79] are also shown

In addition, in the same irradiations neutron-rich nuclides of ${ }^{238} \mathrm{~Pa},{ }^{237} \mathrm{Th}$ and ${ }^{236} \mathrm{Ac}$ have also been observed as a result of (n, p) nuclear charge-exchange reactions [81]. The process is rather complicated for the production of these isotopes, because in each case after removal of protons one neutron was picked up via relativistic nucleon-nucleon collisions. Production cross-sections of $10 \mathrm{nb}(\approx 1$ particle/day $)$ is the current limit for the isotope production at the present GSI FRS facility.

Our experiments on transfer reactions revealed that the region between $\mathrm{Pb}$ and $\mathrm{U}$ is also populated quite strongly in MNT reactions with actinide targets. In Fig. 11, the isotopic distributions of MNT products from $\mathrm{Ca}+\mathrm{U}$ and $\mathrm{Ca}+\mathrm{Cm}$ [22] collisions are compared with fragmentation results for isotopes of elements $\mathrm{U}, \mathrm{Pa}$, Th and Ac $[68,79]$. For the isotopic distributions of Th and Ac, the cross-section maxima reached in MNT reactions are comparable to the ones from fragmentation reactions and toward the neutron-rich side it is indicated that MNT cross-sections become larger than fragmentation cross-sections. In the case of $\mathrm{U}$ and $\mathrm{Pa}$, fragmentation cross-sections are about 10 times larger than MNT cross-sections. The data points from MNT as well as frag- 


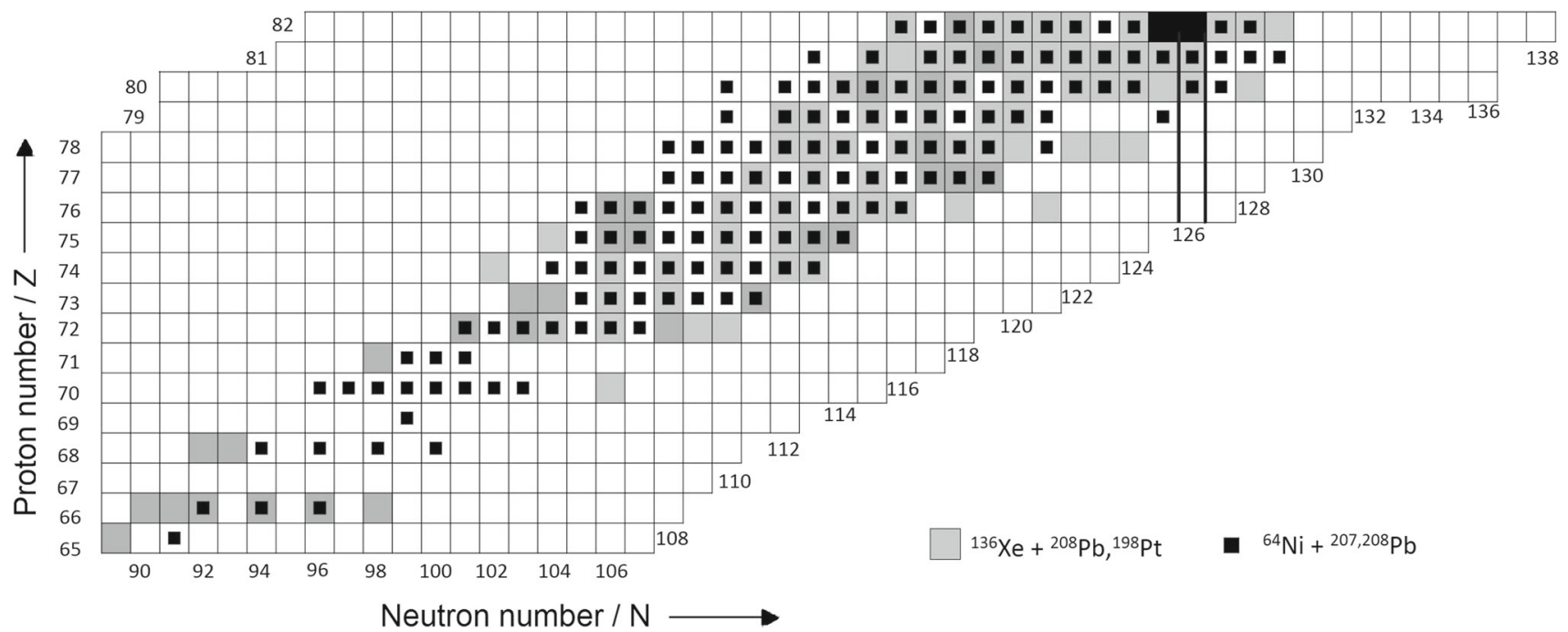

Fig. 12 Section of the nuclide chart showing the transfer products with $65 \leq Z \leq 82$ which were so far observed in experiments of ${ }^{136} \mathrm{Xe}+{ }^{198} \mathrm{Pt}$, ${ }^{208} \mathrm{~Pb}[64,65]$ and ${ }^{64} \mathrm{Ni}+{ }^{207,208} \mathrm{~Pb}[19,63]$
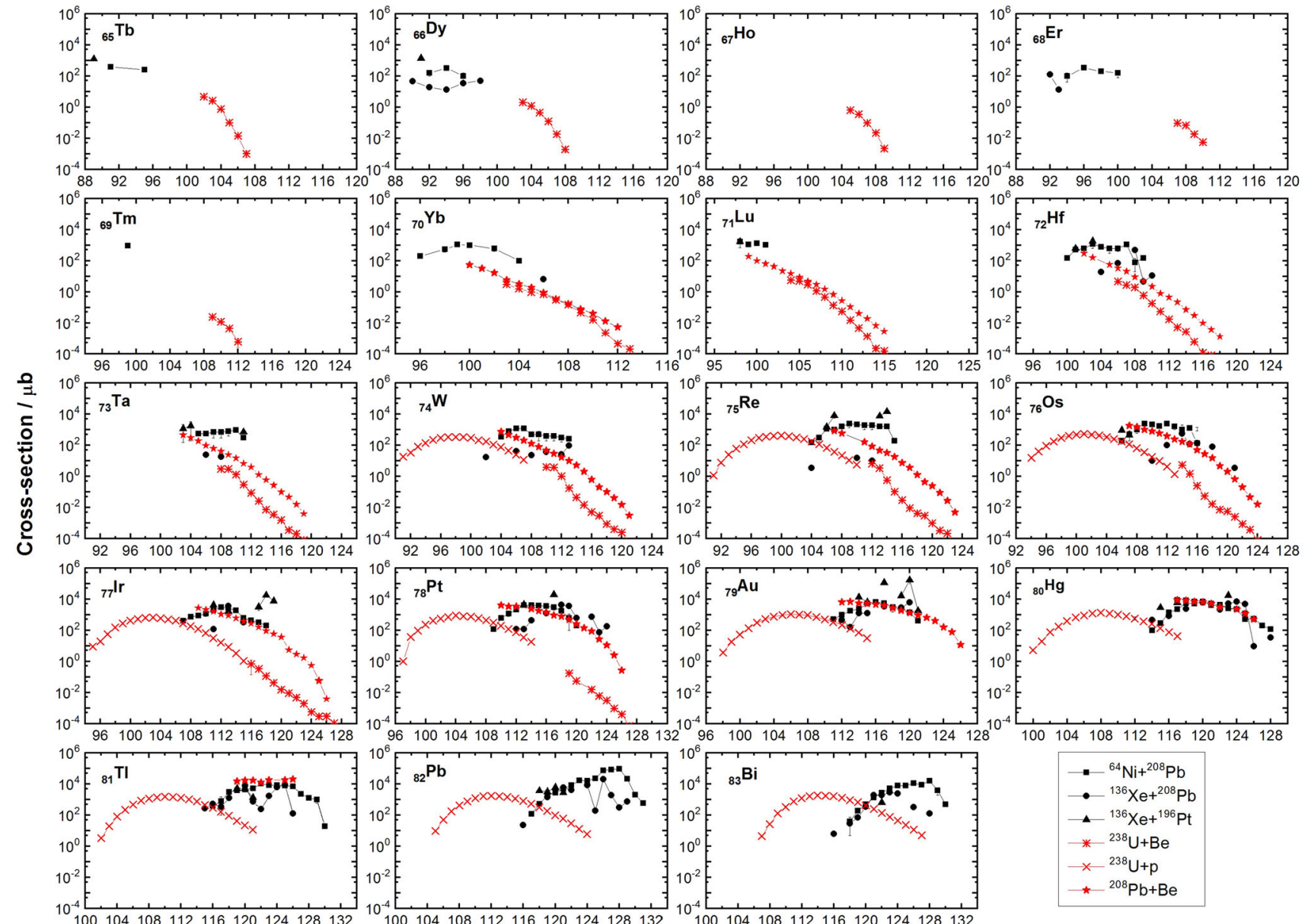

Neutron number / $\mathbf{N}$

Fig. 13 The measured isotopic distributions of transfer products of elements with $65 \leq Z \leq 83$ in collisions of ${ }^{64} \mathrm{Ni}+{ }^{208} \mathrm{~Pb}[63],{ }^{136} \mathrm{Xe}+{ }^{208} \mathrm{~Pb}$ $[64],{ }^{136} \mathrm{Xe}+{ }^{198} \mathrm{Pt}[65]$ are compared with fragmentation reactions of ${ }^{238} \mathrm{U}(1 \mathrm{GeV} / \mathrm{u})+\mathrm{Be}[2],{ }^{238} \mathrm{U}(1 \mathrm{GeV} / \mathrm{u})+{ }^{1} \mathrm{H}[68]$ and ${ }^{208} \mathrm{~Pb}(1 \mathrm{GeV} / \mathrm{u})+{ }^{9} \mathrm{Be}$ [67] 
mentation reactions end on the neutron-rich side shortly after the maxima are reached. The cross-sections are still huge in this region with values between $100 \mu \mathrm{b}$ and $1 \mathrm{mb}$, and it is obvious that they are not the reason for the cut-off. Actually, the reason is the lack of additional neutrons in the projectile nucleus in fragmentation reactions and the lack of suitable detection techniques in the case of MNT reactions (see Sect. $5)$.

\subsection{Neutron-rich isotopes with $Z<82$}

It is expected that the maxima observed in the solar abundance distributions at mass number around $A=195$ are populated from the remnants of the r-process last waiting point nuclei along the $N=126$ neutron shell. These nuclei are likely to be produced at extreme stellar conditions of very high temperature and neutron densities. Still there is no conclusive evidence from the experiments due to the scarcity of measured data along $N=126$ for elements $Z \leq 80$. Presently, ${ }^{202} \mathrm{Os}$ is the lightest known $N=126$ isotone. It was populated in two separate experiments in projectile fragmentation of ${ }^{208} \mathrm{~Pb}$ [1] and ${ }^{238} \mathrm{U}$ [2] beams at $1 \mathrm{GeV} / \mathrm{u}$ at the GSI FRS facility. The measured production cross-section for ${ }^{202} \mathrm{Os}$ is 4.4 picobarn [2] and is nearly the limit cross-section of the present FRS facility.

In the following we give an impression how the crosssections and yields in MNT reactions compare to fragmentation results. We base our discussion on the results of so far performed experiments [3-23] and on theoretical predictions [24-31]. Between 2003 and 2019 transfer reactions in the collision systems ${ }^{64} \mathrm{Ni}+{ }^{207,208} \mathrm{~Pb}[19,63],{ }^{136} \mathrm{Xe}+{ }^{208} \mathrm{~Pb}$ [64], ${ }^{136} \mathrm{Xe}+{ }^{198} \mathrm{Pt}[65,66]$ have been experimentally investigated. The identified nuclei for the region of $65 \leq Z \leq 82$ are shown in the nuclide chart in Fig. 12. The isotopic identification of the heavy target-like transfer products was performed in these experiments [19,63-65] via the $\gamma$-decay spectroscopy. Only in [66] projectile-like transfer products were identified using the large acceptance magnetic spectrometer VAMOS++. The distribution of the complementary target-like fragments was then deduced from the measured cross-sections of projectile-like nuclei. The chart reveals that the most neutron-rich isotopes of the shown elements were so far produced in fragmentation reactions.

Isotopic distributions of MNT products have been established for the different reactions (see Fig. 13). For the nearly identical collision systems ${ }^{64} \mathrm{Ni}+{ }^{208} \mathrm{~Pb}$ measured in [63] and ${ }^{64} \mathrm{Ni}+{ }^{207} \mathrm{~Pb}$ measured in [19], the cross-sections are in agreement within an order of magnitude for most of the nuclei. The MNT cross-section data for elements $Z=(65-83)$ are compared in Fig. 13 with fragmentation cross-sections for reactions of $1 \mathrm{GeV} / \mathrm{u}{ }^{238} \mathrm{U}$ beams on Be targets [2], ${ }^{238} \mathrm{U}(1 \mathrm{GeV} / \mathrm{u})+\mathrm{p}[68]$ and with ${ }^{208} \mathrm{~Pb}(1 \mathrm{GeV} / \mathrm{u})+\mathrm{Be}$ reactions [67]. The MNT cross-section values are compa-
Table 4 Typical values for beam intensities $\mathrm{N}_{b}$ and target thicknesses $\mathrm{d}_{t}$ (respectively, number of target nuclei $\mathrm{N}_{t}$ ) in multi-nucleon transfer reactions and in fragmentation reactions. For fragmentation reactions we give $N_{b}$ values for $\mathrm{Pb}$ or $\mathrm{U}$ beams. For relatively light beams like $\mathrm{Ca}$ or $\mathrm{Ni}$ intensities of $10^{13}$ can be provided. The product $\mathrm{N}_{b} \times \mathrm{N}_{t}$, which determines the yields, is also given. The present sensitivities of MNT and fragmentation reactions in the region below $\mathrm{Pb}$ are denoted by the cross-section limits $\sigma_{\min }$ in the last row

\begin{tabular}{lll}
\hline & MNT reactions & Fragmentation \\
\hline $\mathrm{N}_{b}$ [particles $\left./ \mathrm{s}\right]$ & $10^{10}-10^{13}$ & $10^{10}$ \\
$\mathrm{~d}_{t}\left[\mathrm{mg} / \mathrm{cm}^{2}\right]$ & $1-50$ & $1000-10000$ \\
$\mathrm{~N}_{t}\left[1 / \mathrm{cm}^{2}\right]$ & $10^{18}-5 \times 10^{19}$ & $10^{23}-10^{24}$ \\
$\mathrm{~N}_{b} \times \mathrm{N}_{t}\left[\mathrm{~s}^{-1} \mathrm{~cm}^{-2}\right]$ & $\leq 5 \times 10^{32}$ & $\leq 10^{34}$ \\
$\sigma_{\text {min }}$ & $>1 \mu \mathrm{b}$ & $>1 \mathrm{pb}$ \\
\hline
\end{tabular}

rable in many cases to fragmentation cross-sections, and in some cases even larger cross-sections are measured in MNT reactions.

An interesting observation is reported in [66] from MNT reactions of ${ }^{136} \mathrm{Xe}+{ }^{198} \mathrm{Pt}$ measured at GANIL at the beam energy of $7.98 \mathrm{MeV} / \mathrm{u}$. A strong increase of MNT crosssections compared to fragmentation for isotopes toward the neutron-rich side was observed. However, in this experiment the heavy target-like MNT product was not detected directly. Only the projectile-like fragments were measured at the VAMOS spectrometer around the grazing angle $\left(33^{\circ}\right)$. The cross-sections for the (target-like) isotopes W, Re, Os, Ir and Pt have been deduced from the measured isotopically identified projectile-like products [66] by assuming binary kinematics and including particle evaporation from both fragments. The detected $\gamma$-rays confirmed the production of corresponding target-like products. The detection of unknown nuclei by $\gamma$-decays requires knowledge about the decay scheme. The most neutron-rich isotopes were expected to be produced in reactions associated with small kinetic energy loss. With decreasing proton number of neutron-rich below-Pb nuclei they observed a strong increase of the MNT cross-sections compared to fragmentation cross-sections. For $N=126$ isotones, the cross-section for $Z=77$ is already five orders of magnitude larger in MNT reactions. In the data of directly identified target-like nuclei, this trend is slightly indicated, but available information from neutron-rich nuclei is not sufficient to confirm it. However, model calculations for $\mathrm{Xe}+\mathrm{Pb}$ collisions [39] also reveal this trend.

The experimental conditions in MNT and fragmentation reactions are quite different concerning the applicable target thicknesses and beam intensities. This affects the resulting isotope yields which depend on the product of beam intensity and number of target atoms. Typical parameters are given in Table 4. In Fig. 14 we show an example for yields which could be expected for $\operatorname{Pt}(Z=78)$ isotopes in MNT and in fragmentation reactions for the parameters denoted in the fig- 


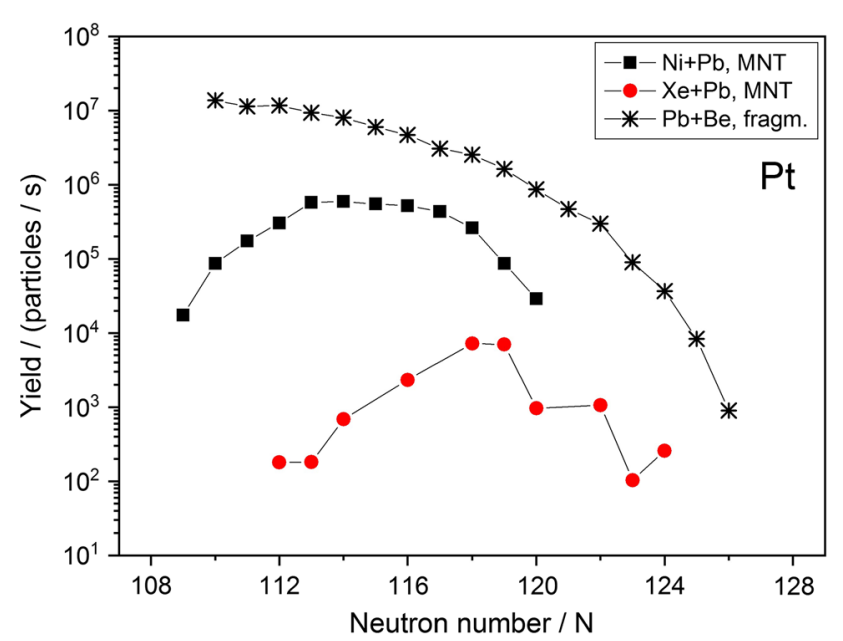

Fig. 14 An example for the yields which can be expected for $\mathrm{Pt}$ $(Z=78)$ isotopes in fragmentation reactions of ${ }^{208} \mathrm{~Pb}(1 \mathrm{GeV} / \mathrm{u})+\mathrm{Be}$ and in transfer reactions of ${ }^{64} \mathrm{Ni}+{ }^{208} \mathrm{~Pb}$ and ${ }^{136} \mathrm{Xe}+{ }^{208} \mathrm{~Pb}$. All underlying cross-sections were taken from experimental data $[2,63,64]$ (see Fig. 13). The realistic values for beam intensities and target thicknesses were taken as follows. For fragmentation: $\mathrm{N}_{b}(P b)=$ $10^{10} / \mathrm{s}, \mathrm{d}_{t}(B e)=5 \mathrm{~g} / \mathrm{cm}^{2} ;$ MNT: $\mathrm{N}_{b}(N i)=10^{12} / \mathrm{s}, \mathrm{d}_{t}(P b)=$ $50 \mathrm{mg} / \mathrm{cm}^{2}, \mathrm{~N}_{b}(X e)=10^{10} / \mathrm{s}, \mathrm{d}_{t}(P b)=50 \mathrm{mg} / \mathrm{cm}^{2}$

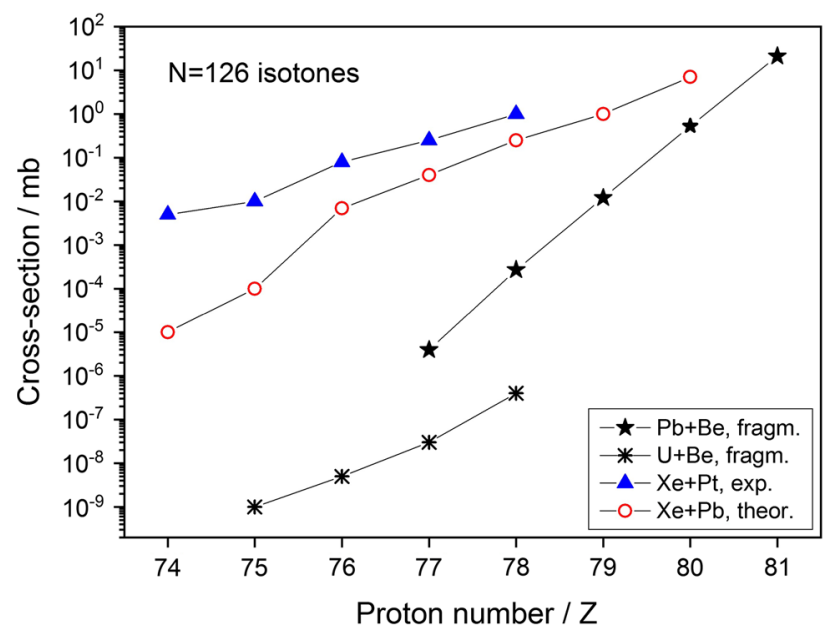

Fig. 15 Cross-sections of $N=126$ isotones with the given $\mathrm{Z}$ from transfer and fragmentation reactions. We made this figure according to [66] and added the graphs for $U+B e$ fragmentation reactions [2] and calculated cross-sections for transfer reactions in $\mathrm{Xe}+\mathrm{Pb}$ [39]

ure caption. The trend is clearly visible. The MNT yields with $\mathrm{Ni}$ beams are large because $\mathrm{Ni}$ can be delivered with higher intensities as heavier beams like $\mathrm{Xe}, \mathrm{Pb}$ or $\mathrm{U}$. But the isotope distributions are quite neutron-deficient. The yield curve for $\mathrm{Xe}+\mathrm{Pb}$ MNT reactions is more neutron-rich, but the smaller intensities of the Xe beams lead to smaller yields. The highest yields can be expected from fragmentation reactions of $\mathrm{Pb}$ beams caused by the much thicker targets. The curves indicate that the cross-sections in MNT reactions should be significantly larger than fragmentation cross-sections to make them profitable. And indeed, this increase of MNT cross- sections with respect to fragmentation cross-sections is indicated for very neutron-rich MNT products below $Z=77$ by the results of [66] and also by model calculations (see Fig. 15).

One has to note that the above given yields are expected at the target and do not yet include the efficiencies of the experimental setups. In projectile fragmentation reactions the efficiencies are large. For the reaction $\mathrm{U}+\mathrm{Be}$ at $1 \mathrm{GeV} / \mathrm{u}$ an efficiency of (40-60)\% is given in [2]. In MNT reactions the efficiencies are much less. At SHIP, the bottleneck is the angular acceptance which was $\approx 0.5 \%$ for $\mathrm{Ni}+\mathrm{Pb}$ and $\mathrm{Ca}+\mathrm{U}$ reactions. For the thick-target experiments efficiencies are not given in refs. [63-65], but it is realistic that they are smaller than $10 \%$. The small efficiencies are connected with the isotope identification via the $\gamma$ decay in MNT experiments.

\section{Experimental challenges}

Many efforts are presently put in the development of separation and detection techniques for heavy MNT products, which must be sensitive enough to allow the detection of nuclei with picobarn cross-sections. The wide angular and energy distributions of low-energy MNT products make separation from background events difficult. Our method to use in-flight separation by velocities allowed us to reach total cross-section limits of $0.5 \mathrm{nb}$ for $\alpha$ emitters which was so far the smallest limit cross-section in MNT experiments. But the angular efficiency on the scale of one percent leads to large losses of events. The approach by another group, to use chemical separation techniques allows the $4 \pi$ collection of MNT products and lead to a sensitivity of $20 \mathrm{nb}$ for $\alpha$ emitters. However, the minimum time for one detection cycle is $1 \mathrm{~min}$ which is too long for the separation of neutron-rich nuclei below $\mathrm{Pb}$ which reach half-lives on the millisecond scale.

Still more problematic is the direct identification of very heavy MNT products with masses around A $\sim 200$ and beyond. Due to the pulse height deficit of the heavy and low energetic MNT products, the A and Z identification cannot be performed with the universal E- $\Delta \mathrm{E}-\mathrm{TOF}$ technique. Therefore, these nuclei are so far identified by their radioactive decays. These are very sensitive for $\alpha$ emitters where principally one decay chain is sufficient to pin down the isotope. But for $\beta$ emitters, $\gamma$ decay spectroscopy must be used where the small peak-to-background ratio restricts the sensitivity to cross-sections larger than $1 \mu \mathrm{b}$. Also, the method is only applicable if excited states in the daughter nucleus are populated with sufficient branching and if the $\gamma$ transitions in the daughter nucleus are already well known.

To overcome the bottleneck of isotope identification, two alternative approaches are presently investigated, one of them 


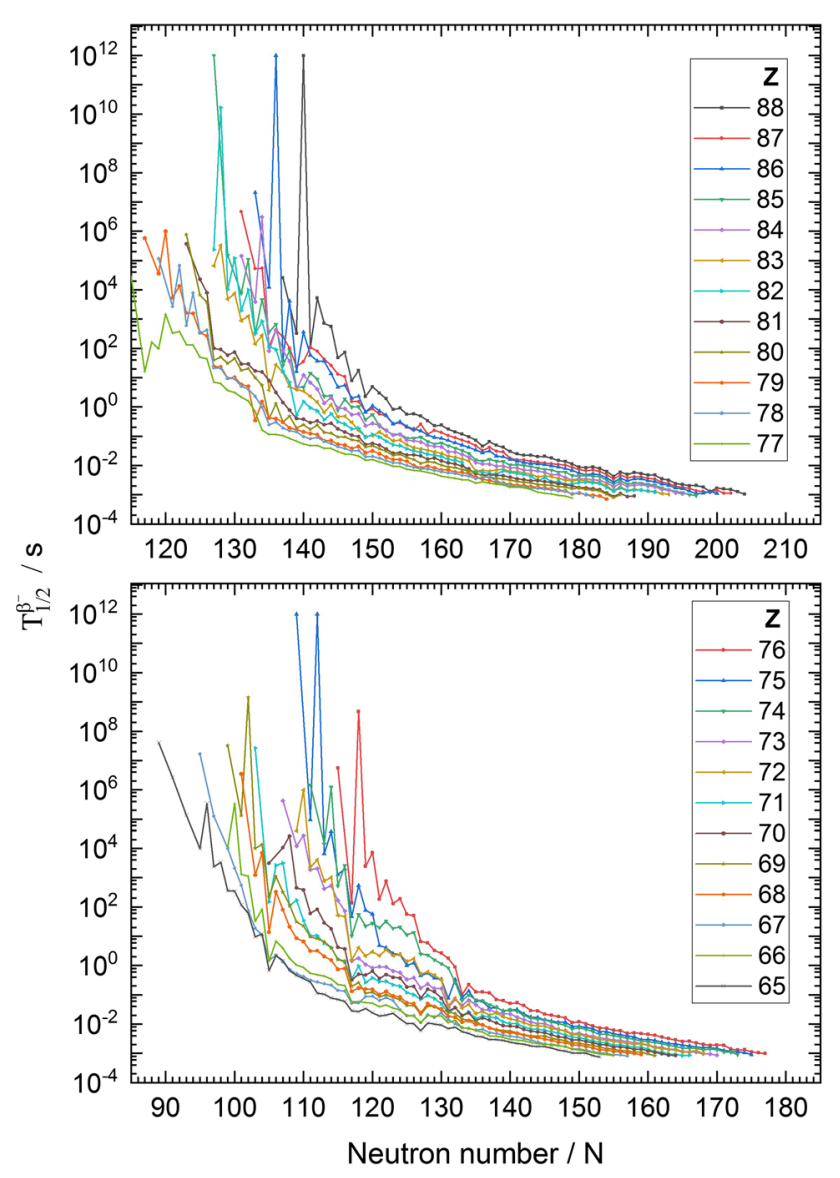

Fig. 16 Calculated $\beta$-decay half-lives for neutron-rich isotopes of elements from $Z=65$ to 88 . The calculated values were taken from [84]

is the application of high-precision mass measurements with a multi-reflection time-of-flight mass spectrometer (MRTOF-MS) $[82,83]$ which is presently tested at the Fragment Separator Facility FRS at GSI. It allows the direct and very precise measurement of the nuclide mass with resolutions in the range $10^{-5}$ to $10^{-6}$ which is mostly sensitive enough to resolve also the isobars. The lower half-live limit is about 10 $\mathrm{ms}$, given by the stopping and extraction time of the nuclei from the ion catcher which is used to slow down the ions before injection into the MR-TOF-MS. The estimated $\beta$ decay half-lives in [84] are greater than $10 \mathrm{~ms}$ for the below$\mathrm{Pb} \mathrm{N}=126$ isotones down to $\mathrm{Z}=65$ (see Fig. 16) which could be accessible with this method. According to simulations, the MR-TOF-MS method is presently limited to cross-sections of minimum $100 \mu \mathrm{b}$ [85]. In order to avoid space charge effects in the ion catcher, the maximum beam intensity is limited. Estimates for uranium beams arrived at maximum intensities of $10^{7}$ ions/s.

Also at Argonne National Laboratory, USA, a new facility using an MR-TOF for mass measurements is under construction [86]. The transfer products will be stopped in a high-intensity RF gas catcher and transported then into the low energy beamline for mass separation using a medium resolution electromagnetic separator $(\Delta \mathrm{m} / \mathrm{m} \simeq 1 / 1500)$. Then, bunching in an RFQ buncher, followed by mass measurements with the MR-TOF $(\Delta \mathrm{m} / \mathrm{m} \simeq 1 / 100,000)$ and spectroscopic investigations will be performed.

Investigations are also undertaken to increase the A and $\mathrm{Z}$ resolution of the large acceptance magnetic spectrometers such as VAMOS++ at GANIL [87] and PRISMA at Legnaro [51]. Also, MNT reactions using inverse kinematics are investigated there. The recent investigations at PRISMA were successful in the identification of reaction products up to the $\mathrm{A} \sim 130$ mass region [88-90].

Another possible method of isotope identification is the selective laser ionization of the MNT products. A dedicated facility named KEK Isotope Separation System (KISS) is developed at the Radioactive Ion Beam Factory at RIKEN specifically for the investigation of neutron-rich MNT products below $\mathrm{Pb}$ [91]. The MNT products are stopped in an argon gas-filled ion catcher. The ion catcher is doughnutshaped to prevent the primary beam from entering the cell. Laser resonance ionization inside the ion catcher is used for $\mathrm{Z}$ selection. After extraction from the gas cell, the laser ionized reaction products are passing a mass separator. The selected ions are then guided to a detection system to perform spectroscopy studies. The method is applicable for ions with a lifetime of $1 \mathrm{~s}$ or more. This is mainly determined by the extraction times from the gas catcher which are about 0.5 $\mathrm{s}$. The overall efficiency of the present KISS setup is on the scale of $0.1 \%$.

\section{Summary and conclusions}

The possibility to synthesize neutron-rich nuclei below $\mathrm{Pb}$ in multi-nucleon transfer reactions was so far studied by different groups in experiments of ${ }^{64} \mathrm{Ni}+{ }^{207,208} \mathrm{~Pb},{ }^{136} \mathrm{Xe}+{ }^{208} \mathrm{~Pb}$ and ${ }^{136} \mathrm{Xe}+{ }^{196} \mathrm{Pt}$. We made a systematic comparison of the published data to find out, which reaction systems lead to the largest cross-sections for neutron-rich isotopes. Also, we presented our new MNT reaction results from collisions of ${ }^{48} \mathrm{Ca}+{ }^{238} \mathrm{U}$ at the SHIP velocity filter where we identified nuclides in the region from $\mathrm{Tl}$ to $\mathrm{Np}(Z=81$ to 93$)$. In the below-Pb region, sufficient experimental MNT data are only available for $\mathrm{Ni}+\mathrm{Pb}$. Therefore, we completed the missing experimental information for ${ }^{48} \mathrm{Ca}+{ }^{238} \mathrm{U}$ and ${ }^{136} \mathrm{Xe}+{ }^{208} \mathrm{~Pb}$ collisions by available model calculations. Our analysis leads to the following conclusions.

- Experimental and theoretical data from MNT reactions indicate that $\mathrm{Xe}$ beams on $\mathrm{Pb}$ target lead to the largest cross-sections of neutron-rich below-Pb isotopes. Also model calculations for $\mathrm{Ca}+\mathrm{U}$ reveal similarly neutron- 
rich isotope distributions but with smaller cross-sections, especially toward the neutron-rich side. More experimental data are needed to confirm this trend. If confirmed, $\mathrm{Ca}+\mathrm{U}$ collisions might nevertheless compete with $\mathrm{Xe}+\mathrm{Pb}$, because $\mathrm{Ca}$ beams are available with higher intensities than the heavier Xe beams, resulting in accordingly larger yields.

- In the below-Pb region, fragmentation reactions compete with MNT reactions. For neutron-rich fragments down to $\mathrm{Z} \approx 75$, fragmentation of $\mathrm{Pb}$ beams results in the largest cross-sections while for isotopes with $Z<75$, the largest cross-sections are measured in fragmentation of $U$ beams. Experimental and theoretical data indicate, however, that MNT cross-sections from $\mathrm{Xe}+\mathrm{Pb}, \mathrm{Pt}$ collisions become many orders higher than fragmentation cross-sections for decreasing $\mathrm{Z}$ of the transfer products and toward increasing neutron-number.

- For a given cross-section, the yields in fragmentation reactions are normally larger than in MNT reactions because of the $\sim 1000$ times larger target thicknesses and larger efficiencies of the separation and detection setups. This should be individually considered for experiments where both reaction types principally allow to produce an isotope.

- The applicability of fragmentation reactions naturally ends at reaction products with neutron numbers exceeding the neutron number of the beam particle. In this case, MNT reactions are the only alternative to produce nuclei with higher number of neutrons. One such region is between $Z=82$ and $Z=92$ where MNT reactions seem very suitable to synthesize new isotopes close to and beyond $N=146$. Transfer cross-sections are large in this region, and indicate reaching values of millibarns for still unknown isotopes. But their observation is so far prevented by the lack of suitable detection techniques. The same is also valid in the region below $\mathrm{Pb}$.

- The main bottleneck in MNT reactions is the lack of a universal detection technique which allows the $\mathrm{A}$ and $\mathrm{Z}$ identification of very heavy MNT products with masses around $\mathrm{A} \sim 200$ and above. The present method of $\gamma$ decay spectroscopy for the neutron-rich $\beta$ emitters is restricted to isotopes with appropriate half-lives and with already known $\gamma$ transitions. The so far reached limit cross-sections of $>1 \mu \mathrm{b}$ are not sensitive enough to observe new neutron-rich isotopes.

- For future experiments, further MNT data with Xe beams and also for collisions of $\mathrm{Ca}+\mathrm{U}$ remain interesting to confirm or disproof the above discussed trends which are indicated by model calculations and by the still quite scarce experimental data. For $\beta$ emitters it was so far found that the velocity filter method and the thick-target experiments lead to the same detection sensitivity. But thick-target experiments have the advantage of $4 \pi$ detec- tion of MNT products and provide higher yields because of the much larger target thicknesses. Therefore they seem better suitable for experiments in the region of $\beta$ emitters. Beside, reactions with relatively symmetric collision systems like $\mathrm{Xe}+\mathrm{Pb}$ are not suitable for velocity filters because the separation of primary beam from target-like reaction products fails more and more with increasing symmetry of the collision system.

Acknowledgements We gratefully acknowledge the support of this project and of one of us (HMD) by grants of the Deutsche Forschungsgemeinschaft (DFG) Ref. No. DE 2946/1-1 and HE 5469/3-1.

Funding Open Access funding provided by Projekt DEAL.

Data Availability Statement This manuscript has no associated data or the data will not be deposited. [Authors' comment: Any data that support the findings of this study are included within the article.]

Open Access This article is licensed under a Creative Commons Attribution 4.0 International License, which permits use, sharing, adaptation, distribution and reproduction in any medium or format, as long as you give appropriate credit to the original author(s) and the source, provide a link to the Creative Commons licence, and indicate if changes were made. The images or other third party material in this article are included in the article's Creative Commons licence, unless indicated otherwise in a credit line to the material. If material is not included in the article's Creative Commons licence and your intended use is not permitted by statutory regulation or exceeds the permitted use, you will need to obtain permission directly from the copyright holder. To view a copy of this licence, visit http://creativecomm ons.org/licenses/by/4.0/.

\section{References}

1. S.J. Steer, Z. Podolyák, S. Pietri, M. Górska, G.F. Farrelly, P.H. Regan, D. Rudolph, A.B. Garnsworthy, R. Hoischen, J. Gerl et al., Int. J. Mod. Phys. E 18, 1002 (2009)

2. J. Kurcewicz, F. Farinon, H. Geissel, S. Pietri, C. Nociforo, A. Prochazka, H. Weick, J.S. Winfield, A. Estradé, P.R.P. Allegro et al., Phys. Lett. B 717, 371 (2012)

3. M. Schädel, J.V. Kratz, H. Ahrens, W. Brüchle, G. Franz, H. Gäggeler, I. Warnecke, G. Wirth, G. Herrmann, N. Trautmann et al., Phys. Rev. Lett. 41, 469 (1978)

4. D.C. Hoffman, M.M. Fowler, W.R. Daniels, H.R. von Gunten, D. Lee, K.J. Moody, K. Gregorich, R. Welch, G.T. Seaborg, W. Brüchle et al., Phys. Rev. C 31, 1763 (1985)

5. K.J. Moody, D. Lee, R.B. Welch, K.E. Gregorich, G.T. Seaborg, R.W. Lougheed, E.K. Hulet, Phys. Rev. C 33, 1315 (1986)

6. M. Schädel, W. Brüchle, H. Gäggeler, J.V. Kratz, K. Sümmerer, G. Wirth, G. Herrmann, R. Stakemann, G. Tittel, N. Trautmann et al., Phys. Rev. Lett. 48, 852 (1982)

7. H. Gäggeler, W. Brüchle, M. Brügger, M. Schädel, K. Sümmerer, G. Wirth, J.V. Kratz, M. Lerch, T. Blaich, G. Herrmann et al., Phys. Rev. C 33, 1983 (1986)

8. K.E. Gregorich, K.J. Moody, D. Lee, K.W. Kot, R.B. Welch, A.P. Wilmarth, G.T. Seaborg, Phys. Rev. C 35, 2117 (1987)

9. K.J. Moody, W. Brüchle, M. Brügger, H. Gäggeler, B. Haefner, M. Schädel, K. Sümmerer, H. Tetzlaff, G. Herrmann, N. Kaffrell et al., Z. Phys. A 328, 417 (1987)

10. R.M. Chasteler, R.A. Henderson, D. Lee, K.E. Gregorich, J.M. Nurmia, R.B. Welch, D.C. Hoffman, Phys. Rev. C 36, 1820 (1987) 
11. A. Türler, H.R. von Gunten, J.D. Leyba, D.C. Hoffman, D.M. Lee, K.E. Gregorich, D.A. Bennett, R.M. Chasteler, C.M. Gannett, H.L. Hall et al., Phys. Rev. C 46, 1364 (1992)

12. S. Heinz, V. Comas, F.P. Heßberger, S. Hofmann, D. Ackermann, H.G. Burkhard, Z. Gan, J. Heredia, J. Khuyagbaatar, B. Kindler et al., Eur. Phys. J. A 38, 227 (2008)

13. S. Heinz, Int. J. Mod. Phys. E 19(17), 2231 (2008)

14. S. Heinz, V. Comas, S. Hofmann, D. Ackermann, J. Heredia, F.P. Heßberger, J. Khuyagbaatar, B. Kindler, B. Lommel, R. Mann, Eur. Phys. J. A 43, 181 (2010)

15. S. Heinz, V. Comas, S. Hofmann, D. Ackermann, J. Heredia, F.P. Heßberger, J. Khuyagbaatar, B. Kindler, B. Lommel, R. Mann et al., Nucl. Phys. A 834, 362c (2010)

16. S. Heinz, V. Comas, S. Hofmann, D. Ackermann, J. Heredia, F.P. Heßberger, J. Khuyagbaatar, B. Kindler, B. Lommel, R. Mann, J. Phys. Conf. Ser. 282, 012007 (2011)

17. V. Comas, S. Heinz, S. Hofmann, D. Ackermann, J. Heredia, F.P. Heßberger, J. Khuyagbaatar, B. Kindler, B. Lommel, R. Mann, Eur. Phys. J. A 48, 180 (2012)

18. V.F. Comas, S. Heinz, S. Hofmann, D. Ackermann, J.A. Heredia, F.P. Heßberger, J. Khuyagbaatar, B. Kindler, B. Lommel, R. Mann, Eur. Phys. J. A 49, 1 (2013)

19. O. Beliuskina, S. Heinz, V. Zagrebaev, V. Comas, C. Heinz, S. Hofmann, R. Knöbel, M. Stahl, D. Ackermann, F.P. Heßberger et al., Eur. Phys. J. A 50, 161 (2014)

20. S. Heinz, O. Beliuskina, V. Comas, H.M. Devaraja, C. Heinz, S. Hofmann, E. Kozulin, F. Morherr, G. Münzenberg, D. Ackermann et al., Eur. Phys. J. A 51, 140 (2015)

21. H.M. Devaraja, S. Heinz, O. Beliuskina, V. Comas, S. Hofmann, C. Hornung, G. Münzenberg, K. Nishio, D. Ackermann, Y.K. Gambhir et al., Phys. Lett. B 748, 199 (2015)

22. S. Heinz, H.M. Devaraja, O. Beliuskina, V. Comas, S. Hofmann, C. Hornung, G. Münzenberg, D. Ackermann, M. Gupta, R.A. Henderson et al., Eur. Phys. J. A 52, 278 (2016)

23. H.M. Devaraja, S. Heinz, O. Beliuskina, S. Hofmann, C. Hornung, G. Münzenberg, D. Ackermann, M. Gupta, Y.K. Gambhir, R.A. Henderson et al., Eur. Phys. J. A 55, 25 (2019)

24. E.M. Kozulin, E. Vardaci, G.N. Knyazheva, A.A. Bogachev, S.N. Dmitriev, I.M. Itkis, M.G. Itkis, A.G. Knyazev, T.A. Loktev, K.V. Novikov et al., Phys. Rev. C 86, 044611 (2012)

25. G.G. Adamian, N.V. Antonenko, W. Scheid, V.V. Volkov, Nucl. Phys. A 627, 361 (1997)

26. G.G. Adamian, N.V. Antonenko, W. Scheid, Phys. Rev. C 68, 034601 (2003)

27. G.G. Adamian, N.V. Antonenko, A.S. Zubov, Phys. Rev. C 71, 034603 (2005)

28. Z.-Q. Feng, G.-M. Jin, J.-Q. Li, Phys. Rev. C 80, 067601 (2009)

29. G.G. Adamian, N.V. Antonenko, V.V. Sargsyan, W. Scheid, Phys. Rev. C 81, 057602 (2010)

30. Z.-Q. Feng, Phys. Rev. C 95, 024615 (2017)

31. L. Zhu, J. Su, P.-W. Wen, Phys. Rev. C 95, 044608 (2017a)

32. L. Zhu, J. Su, F.-S. Zhang, Nucl. Phys. A 964, 93 (2017b)

33. L. Zhu, J. Su, W.-J. Xie, F.-S. Zhang, Phys. Lett. B 767, 437 (2017c)

34. V. Zagrebaev, W. Greiner, J. Phys. G Nucl. Part. Phys. 31, 825 (2005)

35. V. Zagrebaev, W. Greiner, J. Phys. G Nucl. Part. Phys. 35, 125103 (2008a)

36. V. Zagrebaev, W. Greiner, Phys. Rev. C 78, 034610 (2008b)

37. V. Zagrebaev, W. Greiner, Phys. Rev. Lett. 101, 122701 (2008c)

38. V. Zagrebaev, W. Greiner, Nucl. Phys. A 834, 366c (2010)

39. A.V. Karpov, V.V. Saiko, Phys. Rev. C 96, 024618 (2017)

40. A. Winther, Nucl. Phys. A 572, 191 (1994)

41. A. Winther, Nucl. Phys. A 594, 203 (1995)

42. E. Vigezzi, A. Winther, Ann. Phys. (NY) 192, 432 (1989)

43. N. Wang, Z. Li, X. Wu, Phys. Rev. C 65, 064608 (2002)
44. C. Li, F. Zhang, J. Li, L. Zhu, J. Tian, N. Wang, F.-S. Zhang, Phys. Rev. C 93, 014618 (2016)

45. N. Wang, L. Guo, Phys. Lett. B 760, 236 (2016)

46. C. Li, P. Wen, J. Li, G. Zhang, B. Li, X. Xu, Z. Liu, S. Zhu, F.-S. Zhang, Phys. Lett. B 776, 278 (2018)

47. C. Li, X. Xu, J. Li, G. Zhang, B. Li, C.A.T. Sokhna, Z. Ge, F. Zhang, P. Wen, F.-S. Zhang, Phys. Rev. C 99, 024602 (2019)

48. K. Sekizawa, K. Yabana, Phys. Rev. C 88, 014614 (2013)

49. K. Sekizawa, Phys. Rev. C 96, 014615 (2017)

50. V. Volkov, Phys. Rep. 44, 93 (1978)

51. L. Corradi, G. Pollarolo, S. Szilner, J. Phys. G Nucl. Part. Phys. 36, 113101 (2009)

52. F.-S. Zhang, C. Li, L. Zhu, P. Wen, Front. Phys. 13, 132113 (2018)

53. G.G. Adamian, N.V. Antonenko, A. Diaz-Torres, S. Heinz, Eur. Phys. J. A 56, 47 (2020)

54. E. Runte, W.-D. Schmidt-Ott, P. Tidemand-Petersson, R. Kirchner, O. Klepper, W. Kurcewicz, E. Roeckl, N. Kaffrell, P. Peuser, K. Rykaczewski et al., Nucl. Phys. A 399, 163 (1983)

55. U. Bosch, W.-D. Schmidt-Ott, P. Tidemand-Petersson, E. Runte, W Hillebrandt, M. Lechle, F.-K. Thielemann, R. Kirchner, O. Klepper, E. Roeckl et al., Phys. Lett. B 164, 22 (1985)

56. R. Kirchner, O. Klepper, W. Kurcewicz, E. Roeckl, E.F. Zganjar, E. Runte, W.-D. Schmidt-Ott, P. Tidemand-Petersson, N. Kaffrell, P. Peuser et al., Nucl. Phys. A 378, 549 (1982)

57. K. Rykaczewski, R. Kirchner, W. Kurcewicz, D. Schardt, N. Kaffrell, P. Peuser, E. Runte, W.-D. Schmidt-Ott, P. TidemandPetersson, K.-L. Gippert, Z. Phys. A 309, 273 (1983)

58. K. Becker, F. Meissner, W.-D. Schmidt-Ott, U. Bosch, V. Kunze, H. Salewski, R. Kirchner, O. Klepper, E. Roeckl, D. Schardt et al., Nucl. Phys. A 522, 557 (1991)

59. E. Runte, W.-D. Schmidt-Ott, W. Eschner, I. Rosner, R. Kirchner, O. Klepper, K. Rykaczewski, Z. Phys. A 328, 119 (1987)

60. K. Rykaczewski, K.-L. Gippert, N. Kaffrell, R. Kirchner, O. Klepper, V.T. Koslowsky, W. Kurcewicz, W. Nazarewicz, E. Roeckl, E. Runte et al., Nucl. Phys. A 499, 529 (1989)

61. Ch. Wennemann, W.-D. Schmidt-Ott, T. Hild, K. Krumbholz, V. Kunze, F. Meissner, H. Keller, R. Kirchner, E. Roeckl, Z. Phys. A 347, 185 (1994)

62. K.-L. Gippert, E. Runte, W.-D. Schmidt-Ott, P. TidemandPetersson, N. Kaffrell, P. Peuser, R. Kirchner, O. Klepper, W. Kurcewicz, P.O. Larsson et al., Nucl. Phys. A 453, 1 (1986)

63. W. Królas, R. Broda, B. Fornal, T. Pawłat, H. Grawe, K.H. Maier, M. Schramm, R. Schubart, Nucl. Phys. A 724, 289 (2003)

64. J.S. Barrett, W. Loveland, R. Yanez, S. Zhu, A.D. Ayangeakaa, M.P. Carpenter, J.P. Greene, R.V.F. Janssens, T. Lauritsen, E.A. McCutchan et al., Phys. Rev. C 91, 064615 (2015)

65. V.V. Desai, W. Loveland, K. McCaleb, R. Yanez, G. Lane, S.S. Hota, M.W. Reed, H. Watanabe, S. Zhu, K. Auranen et al., Phys. Rev. C 99, 044604 (2019)

66. Y.X. Watanabe, Y.H. Kim, S.C. Jeong, Y. Hirayama, N. Imai, H. Ishiyama, H.S. Jung, H. Miyatake, S. Choi, J.S. Song et al., Phys. Rev. Lett. 115, 172503 (2015)

67. T. Kurtukian-Nieto, J. Benlliure, K.-H. Schmidt, L. Audouin, F. Becker, B. Blank, E. Casarejos, F. Farget, M. Fernández-Ordóñez, J. Giovinazzo et al., Phys. Rev. C 89, 024616 (2014)

68. J. Taïeb, K.-H. Schmidt, L. Tassan-Got, P. Armbruster, J. Benlliure, M. Bernas, A. Boudard, E. Casarejos, S. Czajkowski, T. Enqvist et al., Nucl. Phys. A 724, 413 (2003)

69. S. Hofmann, G. Münzenberg, Rev. Mod. Phys. 72, 733 (2000)

70. S. Hofmann, D. Ackermann, S. Antalic, H.G. Burkhard, V.F. Comas, R. Dressler, Z. Gan, S. Heinz, J.A. Heredia, F.P. Heßberger et al., Eur. Phys. J. A 32, 251 (2007)

71. R. Bass, Nucl. Phys. A 231, 45 (1974)

72. G.G. Adamian, N.V. Antoneno, Private Communication 
73. https://www-nds.iaea.org/relnsd/vcharthtml/VChartHTML.html (IAEA NDS interactive chart of nuclides accessed 15 August 2019)

74. M. Wilpert, B. Gebauer, Th Wilpert, W. von Oertzen, H.G. Bohlen, J. Speer, Phys. Rev. C 51, 680 (1995)

75. D. Brink, Phys. Lett. B 40, 37 (1972)

76. M.G. Itkis, J. Aÿstö, S. Beghini, A.A. Bogachev, L. Corradi, O. Dorvaux, A. Gadea, G. Giardina, F. Hanappe, I.M. Itkis et al., Nucl. Phys. A 734, 136 (2004)

77. V.I. Zagrebaev, W. Greiner, J. Phys. G Nucl. Part. Phys. 34, 1 (2007)

78. C. Golabek, S. Heinz, W. Mittig, F. Rejmund, A.C.C. Villari, S. Bhattacharyva, D. Boilley, G. de France, A. Drouart, L. Gaudefroy et al., Eur. Phys. J. A 43, 251 (2010)

79. J. Kurcewicz, Z. Liu, M. Pfützner, P.J. Woods, C. Mazzocchi, K.-H. Schmidt, A. Kelić, F. Attallah, E. Badura, C.N. Davids et al., Nucl. Phys. A 767, 1 (2006)

80. H. Alvarez-Pol, J. Benlliure, E. Casarejos, L. Audouin, D. CortinaGil, T. Enqvist, B. Fernández-Domínguez, A.R. Junghans, B. Jurado, P. Napolitani et al., Phys. Rev. C 82, 041602 (2010)

81. L. Chen, W.R. Plaß, H. Geissel, R. Knöbel, C. Kozhuharov, YuA Litvinov, Z. Patyk, C. Scheidenberger, K. Siegień-Iwaniuk, B. Sun et al., Phys. Lett. B 691, 234 (2010)

82. W.R. Plaß, T. Dickel, S. Purushothaman, P. Dendooven, H. Geissel, J. Ebert, E. Haettner, C. Jesch, M. Ranjan, M.P. Reiter et al., Nucl. Instrum. Methods Phys. Res. B 317, 457 (2013)
83. T. Dickel, W.R. Plaß, A. Becker, U. Czok, H. Geissel, E. Haettner, C. Jesch, W. Kinsel, M. Petrick, C. Scheidenberger et al., Nucl. Instrum. Methods Phys. Res. A 777, 172 (2015)

84. P. Möller, M.R. Mumpower, T. Kawano, W.D. Myers, At. Data Nucl. Data Tables 125, 1 (2019)

85. T. Dickel et al., Proposal to the G-PAC, proposal number S475 (2018/2019)

86. G. Savard, M. Brodeur, J.A. Clark, R.A. Knaack, A.A. Valverde, Nucl. Instrum. Methods Phys. Res. B 463, 258 (2020)

87. M. Rejmund, B. Lecornu, A. Navin, C. Schmitt, S. Damoy, O. Delaune, J.M. Enguerrand, G. Fremont, P. Gangnant, L. Gaudefroy et al., Nucl. Instrum. Methods Phys. Res. A 646, 184 (2011)

88. F. Galtarossa, L. Corradi, S. Szilner, E. Fioretto, G. Pollarolo, T. Mijatović, D. Montanari, D. Ackermann, D. Bourgin, S. Courtin et al., Phys. Rev. C 97, 054606 (2018)

89. L. Corradi, S. Szilner, G. Pollarolo, E. Fioretto, F. Galtarossa, T. Mijatović ć, A. Gottardo, A.I. Sison, G. Jaworski, T. Marchi, et al., JPS Conf. Proc. 32, 010043 (2020)

90. S. Szilner, L. Corradi, G. Pollarolo, G. Colucci, P. Colović, E. Fioretto, F. Galtarossa, A. Goasduff, T. Marchi, T. Mijatović, et al., EPJ Web Conf. 223, 01064 ( 2019)

91. Y. Hirayama, Y.X. Watanabe, N. Imai, H. Ishiyama, S.C. Jeong, H. Miyatake, M. Oyaizu, S. Kimura, M. Mukai, Y.H. Kim et al., Nucl. Instrum. Methods Phys. Res. B 353, 4 (2015) 